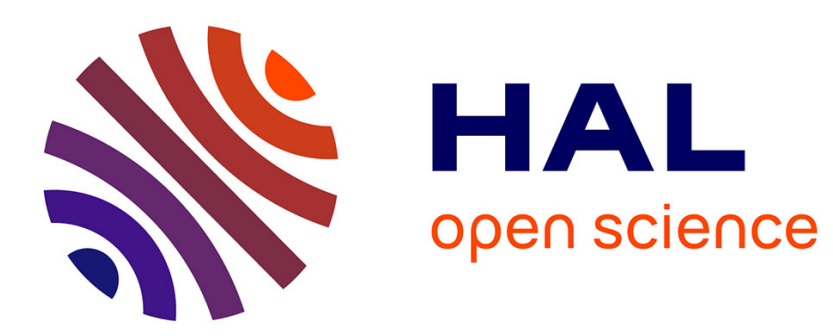

\title{
Boundary homogenization and reduction of dimension in a Kirchhoff-Love plate
}

\author{
Dominique Blanchard, Antonio Gaudiello, Taras A. Mel'Nyk
}

\section{To cite this version:}

Dominique Blanchard, Antonio Gaudiello, Taras A. Mel'Nyk. Boundary homogenization and reduction of dimension in a Kirchhoff-Love plate. 2007. hal-00140073

\section{HAL Id: hal-00140073 https://hal.science/hal-00140073}

Preprint submitted on 4 Apr 2007

HAL is a multi-disciplinary open access archive for the deposit and dissemination of scientific research documents, whether they are published or not. The documents may come from teaching and research institutions in France or abroad, or from public or private research centers.
L'archive ouverte pluridisciplinaire HAL, est destinée au dépôt et à la diffusion de documents scientifiques de niveau recherche, publiés ou non, émanant des établissements d'enseignement et de recherche français ou étrangers, des laboratoires publics ou privés. 


\title{
Boundary homogenization and reduction of dimension in a Kirchhoff-Love plate
}

\author{
Dominique Blanchard, Antonio Gaudiello and Taras A. Mel'nyk
}

\begin{abstract}
We investigate the asymptotic behavior, as $\varepsilon$ tends to $0^{+}$, of the transverse displacement of a Kirchhoff-Love plate composed of two domains $\Omega_{\varepsilon}^{+} \cup \Omega_{\varepsilon}^{-}$, contained in the $\left(x_{1}, x_{2}\right)$-coordinate plane and depending on $\varepsilon$ in the following way. The first domain $\Omega_{\varepsilon}^{-}$is a thin strip with vanishing height $h_{\varepsilon}$ (in direction $x_{2}$ ), as $\varepsilon$ tends to $0^{+}$. The second one $\Omega_{\varepsilon}^{+}$is a comb with fine teeth, having small cross section $\varepsilon \omega$ and constant height, $\varepsilon$-periodically distributed (in direction $x_{1}$ ) on the upper side of the thin strip (see Figure 1). The structure is assumed clamped on the top of the teeth, with a free boundary elsewhere, and subjected to a transverse load. As $\varepsilon$ tends to $0^{+}$, we obtain a "continuum" bending model of rods in the limit domain of the comb, while the limit displacement is independent of $x_{2}$ in the rescaled (with respect to $h_{\varepsilon}$ ) strip. We show that the displacement in the strip is equal to the displacement on the base of the teeth, if $h_{\varepsilon} \gg \varepsilon^{4}$. While, if the strip is thin enough (i.e. $h_{\varepsilon} \simeq \varepsilon^{4}$ ), we show that microscopic oscillations of the displacement in the strip, between the basis of the teeth, may produce a limit average field different from that on the base of the teeth, i.e. a discontinuity in the transmission condition may appear in the limit model.
\end{abstract}

\section{Résumé}

Cet article concerne le comportement asymptotique de la flexion d'une structure bidimensionnelle élastique $\Omega_{\varepsilon}^{+} \cup \Omega_{\varepsilon}^{-}$(contenue dans le plan $\left(x_{1}, x_{2}\right)$ et sous l'hypothèse de Kirchhoff-Love) dont la géométrie dépend d'un petit paramètre $\varepsilon$ de la façon suivante (voir la Figure 1). Le domaine $\Omega_{\varepsilon}^{-}$est une bande d'épaisseur $h_{\varepsilon}$ (dans la direction $x_{2}$ ) qui tend vers 0 avec $\varepsilon$. Le second domaine $\Omega_{\varepsilon}^{+}$est consitué d'un ensemble de créneaux bidimensionnels $\varepsilon$-périodiquement répartis dans la direction $x_{1}$ et de hauteur constante dans la direction $x_{2}$. La structure est encastrée aux sommets des créneaux, libre sur le reste de la frontière et elle est soumise à un champ de forces transverses. A la limite nous obtenons un "continuum" de modèles de poutres en flexion dans le domaine rempli asymptotiquement par les créneaux et un déplacement constant en $x_{2}$ dans la bande (mise à l'échelle par rapport à $h_{\varepsilon}$ ). Nous démontrons que si $h_{\varepsilon} \gg \varepsilon^{4}$, le déplacement dans la bande est égal à celui de la base des créneaux. Par contre, si l'épaisseur de la bande est de l'ordre de $\varepsilon^{4}$, des oscillations microscopiques du déplacement dans la bande entre les bases des créneaux induisent une discontinuité dans la condition de transmission du déplacement pour le modèle limite.

Keywords: Kirchhoff-Love plate, rough boundary, thick junctions, homogenization, dimension reduction.

2000AMS subject classifications: 74K20, 35B27. 


\section{Statement of the problem and main results}

Let $\omega=] a, b[$, with $0<a<b<1, c, d \in] 0,+\infty\left[\right.$, and $\{\varepsilon\}$ and $\left\{h_{\varepsilon}\right\}$ be two sequences of positive numbers converging to zero. For every $\varepsilon$, consider the three-dimensional plate with small thickness $t>0$ and with middle surface $\Omega_{\varepsilon}^{+} \cup \Omega_{\varepsilon}^{-} \subset \mathbb{R}^{2}$ (see Figure 1 ), where

$$
\Omega_{\varepsilon}^{+}=\bigcup_{\{k \in \mathbb{N}: \varepsilon b+\varepsilon k<c\}}(\varepsilon \omega+\varepsilon k) \times[0, d[
$$

is a comb with fine teeth of small cross section $\varepsilon \omega$ and constant height $d, \varepsilon$-periodically distributed on the upper basis of the thin strip:

$$
\left.\Omega_{\varepsilon}^{-}=\right] 0, c[\times]-h_{\varepsilon}, 0[
$$

which has a vanishing height $h_{\varepsilon}$ and constant basis. Moreover, denote with $\Gamma_{\varepsilon}$ the top of the teeth of the middle surface:

$$
\Gamma_{\varepsilon}=\bigcup_{\{k \in \mathbb{N}: \varepsilon b+\varepsilon k<c\}}(\varepsilon \omega+\varepsilon k) \times\{d\}
$$

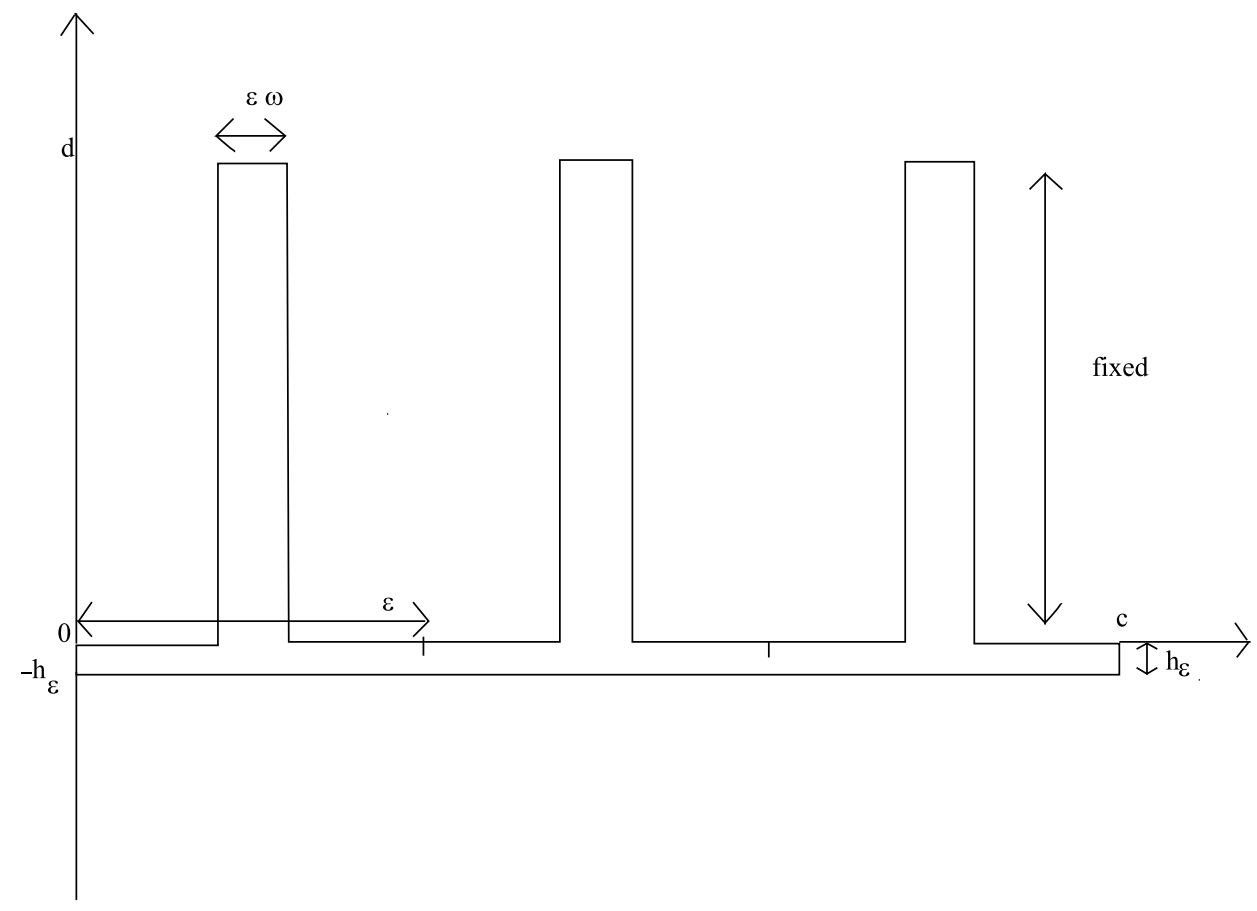

Figure 1: the middle surface of our three-dimensional plate.

When the plate is clamped on $\left.\Gamma_{\varepsilon} \times\right]-\frac{t}{2}, \frac{t}{2}\left[\right.$, with a free boundary on $\left(\partial\left(\Omega_{\varepsilon} \cup \Omega_{\varepsilon}^{-}\right)-\Gamma_{\varepsilon}\right) \times$ ]$-\frac{t}{2}, \frac{t}{2}[$, and it is subjected to a transverse load, the Kirchhoff-Love equation satisfied by 
the transverse displacement $U_{\varepsilon}$ of the middle surface $\Omega_{\varepsilon}^{+} \cup \Omega_{\varepsilon}^{-}$is given by (see pages $205 \div 207$ in $[13])$

$$
\left\{\begin{array}{l}
\frac{E t^{3}}{12\left(1-\mu^{2}\right)} \Delta^{2} U_{\varepsilon}=F_{\varepsilon} \text { in } \Omega_{\varepsilon}^{+} \cup \Omega_{\varepsilon}^{-} \\
U_{\varepsilon}=\partial_{n} U_{\varepsilon}=0 \text { on } \Gamma_{\varepsilon} \\
\Delta U_{\varepsilon}+(1-\mu)\left(2 n_{1} n_{2} \partial_{x_{1} x_{2}}^{2} U_{\varepsilon}-n_{2}^{2} \partial_{x_{1}}^{2} U_{\varepsilon}-n_{1}^{2} \partial_{x_{2}}^{2} U_{\varepsilon}\right)=0 \\
\text { on } \partial\left(\Omega_{\varepsilon}^{+} \cup \Omega_{\varepsilon}^{-}\right) \backslash \Gamma_{\varepsilon} \\
\partial_{n} \Delta U_{\varepsilon}+(1-\mu) \partial_{\tau}\left[n_{1} n_{2}\left(\partial_{x_{2}}^{2} U_{\varepsilon}-\partial_{x_{1}}^{2} U_{\varepsilon}\right)+\left(n_{1}^{2}-n_{2}^{2}\right) \partial_{x_{1} x_{2}}^{2} U_{\varepsilon}\right]=0 \\
\quad \text { on } \partial\left(\Omega_{\varepsilon}^{+} \cup \Omega_{\varepsilon}^{-}\right) \backslash \Gamma_{\varepsilon}
\end{array}\right.
$$

where $F_{\varepsilon} \in L^{2}\left(\Omega^{+} \cup \Omega_{\varepsilon}^{-}\right)$represents the transverse load, $\left.\Omega^{+}=\right] 0, c[\times] 0, d[$ is the "limit domain" of the comb, $n=\left(n_{1}, n_{2}\right)$ and $\tau$ denote the exterior unit normal and the unit tangent to $\Omega_{\varepsilon}^{+} \cup \Omega_{\varepsilon}^{-}$respectively, $\left.\mu \in\right] 0, \frac{1}{2}[$ is the Poisson ratio and $E>0$ is the Young modulus of the plate. In the following, $M$ will denote the flexural rigidity modulus of the plate, i.e.

$$
M=\frac{E t^{3}}{12\left(1-\mu^{2}\right)} .
$$

The weak formulation of Problem (1.1) is the following one (see pages 205-207 in [13]):

$$
\left\{\begin{array}{l}
U_{\varepsilon} \in H^{2}\left(\Omega_{\varepsilon}^{+} \cup \Omega_{\varepsilon}^{-}\right), \quad U_{\varepsilon}=\partial_{n} U_{\varepsilon}=0 \text { on } \Gamma_{\varepsilon}, \\
M \int_{\Omega_{\varepsilon}^{+} \cup \Omega_{\varepsilon}^{-}} \Delta U_{\varepsilon} \Delta V+(1-\mu)\left(2 \partial_{x_{1} x_{2}}^{2} U_{\varepsilon} \partial_{x_{1} x_{2}}^{2} V-\partial_{x_{1}}^{2} U_{\varepsilon} \partial_{x_{2}}^{2} V-\partial_{x_{2}}^{2} U_{\varepsilon} \partial_{x_{1}}^{2} V\right) d x= \\
\int_{\Omega_{\varepsilon}^{+} \cup \Omega_{\varepsilon}^{-}} F_{\varepsilon} V d x, \quad \forall V \in H^{2}\left(\Omega_{\varepsilon} \cup \Omega_{\varepsilon}^{-}\right): V=\partial_{n} V=0 \text { on } \Gamma_{\varepsilon} .
\end{array}\right.
$$

The goal of our paper is to study the asymptotic behavior of Problem (1.3), as $\varepsilon$ tends to zero. To this aim, by following an idea of P.G. Ciarlet (see [9]), Problem (1.3) can be reformulated on a domain independent of $h_{\varepsilon}$, through appropriate rescalings mapping $\Omega_{\varepsilon}^{-}$ into the fixed rectangle: $\left.\Omega^{-}=\right] 0, c[\times]-1,0[$. Namely, by setting

$$
\begin{aligned}
& \begin{cases}f_{\varepsilon}(x)=F_{\varepsilon}(x), & \text { a.e. } x \in \Omega^{+}, \\
f_{\varepsilon}(x)=F_{\varepsilon}\left(x_{1}, h_{\varepsilon} x_{2}\right), & \text { a.e. } x \in \Omega^{-},\end{cases} \\
& \begin{cases}u_{\varepsilon}(x)=U_{\varepsilon}(x), & \text { a.e. } x \in \Omega_{\varepsilon}^{+}, \\
u_{\varepsilon}(x)=U_{\varepsilon}\left(x_{1}, h_{\varepsilon} x_{2}\right), & \text { a.e. } x \in \Omega^{-},\end{cases}
\end{aligned}
$$

and $\Omega_{\varepsilon}=\Omega_{\varepsilon}^{+} \cup \Omega^{-}$, it turns out that $u_{\varepsilon}$ belongs to the following space:

$$
\begin{aligned}
V_{\varepsilon}= & \left\{v \in H^{1}\left(\Omega_{\varepsilon}\right): v^{+} \in H^{2}\left(\Omega_{\varepsilon}^{+}\right), v^{-} \in H^{2}\left(\Omega^{-}\right),\right. \\
& \left.v=0, D v=0 \text { on } \Gamma_{\varepsilon}, \partial_{x_{1}} v^{+}=\partial_{x_{1}} v^{-} \text {on } \Sigma \backslash \partial \Omega_{\varepsilon}, h_{\varepsilon} \partial_{x_{2}} v^{+}=\partial_{x_{2}} v^{-} \text {on } \Sigma \backslash \partial \Omega_{\varepsilon}\right\},
\end{aligned}
$$


where $\left.v^{+}=v_{\Omega_{\varepsilon}^{+}}, v^{-}=v_{\Omega_{\Omega^{-}}}, \Sigma=\right] 0, c\left[\times\{0\}\right.$. Moreover, $u_{\varepsilon}$ is the unique solution of the following problem:

$$
\left\{\begin{array}{l}
u_{\varepsilon} \in V_{\varepsilon} \\
M \int_{\Omega_{\varepsilon}^{+}} \Delta u_{\varepsilon} \Delta v+(1-\mu)\left(2 \partial_{x_{1} x_{2}}^{2} u_{\varepsilon} \partial_{x_{1} x_{2}}^{2} v-\partial_{x_{1}}^{2} u_{\varepsilon} \partial_{x_{2}}^{2} v-\partial_{x_{2}}^{2} u_{\varepsilon} \partial_{x_{1}}^{2} v\right) d x+ \\
+M h_{\varepsilon} \int_{\Omega^{-}}\left(\partial_{x_{1}}^{2} u_{\varepsilon}+\frac{1}{h_{\varepsilon}^{2}} \partial_{x_{2}}^{2} u_{\varepsilon}\right)\left(\partial_{x_{1}}^{2} v+\frac{1}{h_{\varepsilon}^{2}} \partial_{x_{2}}^{2} v\right) d x+ \\
+M(1-\mu) h_{\varepsilon} \int_{\Omega^{-}} 2 \frac{1}{h_{\varepsilon}} \partial_{x_{1} x_{2}}^{2} u_{\varepsilon} \frac{1}{h_{\varepsilon}} \partial_{x_{1} x_{2}}^{2} v-\partial_{x_{1}}^{2} u_{\varepsilon} \frac{1}{h_{\varepsilon}^{2}} \partial_{x_{2}}^{2} v-\frac{1}{h_{\varepsilon}^{2}} \partial_{x_{2}}^{2} u_{\varepsilon} \partial_{x_{1}}^{2} v d x= \\
=\int_{\Omega_{\varepsilon}^{+}} f_{\varepsilon} v d x+h_{\varepsilon} \int_{\Omega^{-}} f_{\varepsilon} v d x, \quad \forall v \in V_{\varepsilon} .
\end{array}\right.
$$

The study of the asymptotic behavior of Problem (1.5) will be performed under the following assumption:

$$
\left\{\begin{array}{l}
f_{\left.\varepsilon\right|_{\Omega^{+}}} \rightarrow f \text { strongly in } L^{2}\left(\Omega^{+}\right) \\
h_{\varepsilon} f_{\left.\varepsilon\right|_{\Omega^{-}}} \rightarrow g \text { strongly in } L^{2}\left(\Omega^{-}\right)
\end{array}\right.
$$

as $\varepsilon$ tends to zero. Moreover, the following spaces will be involved:

$$
W^{2}\left(\Omega^{+}\right)=\left\{v \in L^{2}\left(\Omega^{+}\right): \partial_{x_{2}} v \in L^{2}\left(\Omega^{+}\right), \partial_{x_{2}}^{2} v \in L^{2}\left(\Omega^{+}\right), v=\partial_{x_{2}} v=0 \text { on } \Gamma\right\},
$$

where $\Gamma=] 0, c[\times\{d\}$, and

$$
H_{p e r}^{2}(] 0,1[)=\left\{v \in H^{2}(] 0,1[): v(0)=v(1), v^{\prime}(0)=v^{\prime}(1)\right\},
$$

with $v^{\prime}$ denoting the first derivative of $v$. Remark that $H_{\text {per }}^{2}(] 0,1[)$ is the closure of $C_{p e r}^{\infty}([0,1])$ with respect to the $H^{2}(] 0,1[)$-norm, where $C_{\text {per }}^{\infty}([0,1])$ is the set of functions in $C^{\infty}(\mathbb{R})$ which are 1-periodic.

In the sequel, $\widetilde{v}$ denotes the zero-extension to $\Omega^{+}$of any function $v$ defined in a subset of $\Omega^{+}$, and

$$
|\omega|=b-a,
$$

We will show that the limit problem depends on

$$
\lim _{\varepsilon \rightarrow 0} \frac{\varepsilon^{4}}{h_{\varepsilon}}=l \in[0,+\infty[
$$

and $\int_{-1}^{0} g\left(x_{1}, x_{2}\right) d x_{2}$. Precisely, the following main result will be proved:

Theorem 1.1. Let $u_{\varepsilon}$ be the unique solution of Problem (1.5). Let $W^{2}\left(\Omega^{+}\right)$be the space defined in (1.7). Assume (1.6) and (1.9). Then,

$$
\widetilde{u_{\varepsilon}} \rightarrow|\omega| u \text { weakly in } W^{2}\left(\Omega^{+}\right),
$$




$$
\begin{gathered}
\widetilde{\partial_{x_{1}}^{2} u_{\varepsilon}} \rightarrow-\mu|\omega| \partial_{x_{2}}^{2} u \text { weakly in } L^{2}\left(\Omega^{+}\right), \\
\widetilde{\partial_{x_{1} x_{2}}^{2} u_{\varepsilon}} \rightarrow 0 \text { weakly in } L^{2}\left(\Omega^{+}\right)
\end{gathered}
$$

as $\varepsilon \rightarrow 0$, where $u$ is the unique solution of the following problem:

$$
\left\{\begin{array}{l}
u \in W^{2}\left(\Omega^{+}\right) \\
|\omega| \frac{E t^{3}}{12} \int_{\Omega^{+}} \partial_{x_{2}}^{2} u \partial_{x_{2}}^{2} v d x=|\omega| \int_{\Omega^{+}} f v d x+ \\
+\int_{0}^{c}\left(\int_{-1}^{0} g\left(x_{1}, x_{2}\right) d x_{2}\right) v\left(x_{1}, 0\right) d x_{1} \quad \forall v \in W^{2}\left(\Omega^{+}\right)
\end{array}\right.
$$

with $|\omega|$ defined in (1.8), $\mu \in] 0, \frac{1}{2}[$ the Poisson ratio, $E>0$ the Young modulus and $t$ denoting the small thickness of the $3 d$ plate (see Problem (1.1)), and $f$ and g given by (1.6). Moreover,

$$
\begin{gathered}
\left\|\partial_{x_{2}} u_{\varepsilon}\right\|_{L^{2}\left(\Omega^{-}\right)} \leq c h_{\varepsilon}^{\frac{3}{4}} \\
\left\|\partial_{x_{1} x_{2}}^{2} u_{\varepsilon}\right\|_{L^{2}\left(\Omega^{-}\right)} \leq c h_{\varepsilon}^{\frac{1}{2}}, \quad\left\|\partial_{x_{2}}^{2} u_{\varepsilon}\right\|_{L^{2}\left(\Omega^{-}\right)} \leq c h_{\varepsilon}^{\frac{3}{2}}
\end{gathered}
$$

for every $\varepsilon$, where $c$ is a constant independent of $\varepsilon$, and

$$
u_{\varepsilon} \rightarrow u_{\left.\right|_{\Sigma}}+\int_{0}^{1} v_{0} d y_{1} \text { weakly in } L^{2}\left(\Omega^{-}\right),
$$

as $\varepsilon \rightarrow 0$, where $v_{0}=0$ if $l=0$ in (1.9), while, if $\left.l \in\right] 0,+\infty\left[, v_{0}\left(=v_{0}\left(x_{1}, y_{1}\right)\right)\right.$ is the unique solution of the following problem:

$$
\left\{\begin{array}{l}
v_{0} \in L^{2}(] 0, c\left[, H_{p e r}^{2}(] 0,1[)\right) \\
\left.v_{0}\left(x_{1}, y_{1}\right)=0 \text { in }\right] 0, c[\times \omega \\
\frac{E t^{3}}{12} \frac{1}{l} \int_{] 0, c[\times] 0,1[} \partial_{y_{1}}^{2} v_{0}\left(x_{1}, y_{1}\right) \partial_{y_{1}}^{2} \varphi\left(x_{1}, y_{1}\right) d x_{1} d y_{1}= \\
=\int_{] 0, c[\times] 0,1[}\left(\int_{-1}^{0} g\left(x_{1}, x_{2}\right) d x_{2}\right) \varphi\left(x_{1}, y_{1}\right) d x_{1} d y_{1}, \\
\left.\forall \varphi \in L^{2}(] 0, c\left[, H_{p e r}^{2}(] 0,1[)\right): \varphi\left(x_{1}, y_{1}\right)=0 \text { in }\right] 0, c[\times \omega
\end{array}\right.
$$

with $u_{\left.\right|_{\Sigma}}$ denoting the trace on $\Sigma$ of the solution $u$ of (1.10). Furthermore, the convergence 
of the energies holds:

$$
\begin{aligned}
& \lim _{\varepsilon \rightarrow 0}\left\{\frac{E t^{3}}{12\left(1-\mu^{2}\right)} \int_{\Omega_{\varepsilon}^{+}}\left|\Delta u_{\varepsilon}\right|^{2}+2(1-\mu)\left(\left|\partial_{x_{1} x_{2}}^{2} u_{\varepsilon}\right|^{2}-\partial_{x_{1}}^{2} u_{\varepsilon} \partial_{x_{2}}^{2} u_{\varepsilon}\right) d x+\right. \\
& \left.+\frac{E t^{3}}{12\left(1-\mu^{2}\right)} h_{\varepsilon} \int_{\Omega^{-}}\left|\partial_{x_{1}}^{2} u_{\varepsilon}+\frac{1}{h_{\varepsilon}^{2}} \partial_{x_{2}}^{2} u_{\varepsilon}\right|^{2}+2(1-\mu)\left(\left|\frac{1}{h_{\varepsilon}} \partial_{x_{1} x_{2}}^{2} u_{\varepsilon}\right|^{2}-\frac{1}{h_{\varepsilon}^{2}} \partial_{x_{2}}^{2} u_{\varepsilon} \partial_{x_{1}}^{2} u_{\varepsilon}\right) d x\right\}= \\
& \frac{E t^{3}}{12}\left(|\omega| \int_{\Omega^{+}}\left|\partial_{x_{2}}^{2} u\right|^{2} d x+\frac{1}{l} \int_{] 0, c[\times] 0,1[}\left|\partial_{y_{1}}^{2} v_{0}\left(x_{1}, y_{1}\right)\right|^{2} d x_{1} d y_{1}\right),
\end{aligned}
$$

where $\infty \cdot 0$ means 0 .

Proof. Theorem 1.1 is an immediate consequence of Proposition 3.1, Corollary 3.2, Proposition 4.1 and Proposition 4.2 (see Section 3 and Section 4), by setting $v_{0}\left(x_{1}, y_{1}\right)=u_{0}\left(x_{1}, y_{1}\right)-$ $u_{\left.\right|_{\Sigma}}\left(x_{1}, 0\right)$ in $] 0, c[\times \omega$, and by recalling definition (1.2).

The convergences of the energies is obtained by passing to the limit, as $\varepsilon$ tends to zero, in (1.5) with $v=u_{\varepsilon}$, and by making use of assumption (1.6), of the convergences of $\left\{\widetilde{u}_{\varepsilon}\right\}_{\varepsilon}$, and of the equation satisfied by $u$ and $v_{0}$.

Remark 1.2. Problem (1.10) and Problem (1.12) are the weak formulation of the following problems:

$$
\left\{\begin{array}{l}
\frac{E t^{3}}{12} \frac{\partial^{4} u}{\partial x_{2}^{4}}=f \text { in } \Omega^{+} \\
u=\frac{\partial u}{\partial x_{2}}=0 \text { on } \Gamma \\
\frac{\partial^{2} u}{\partial x_{2}^{2}}=0 \text { on } \Sigma \\
\frac{\partial^{3} u}{\partial x_{2}^{3}}=\frac{12}{|\omega| E t^{3}} \int_{-1}^{0} g\left(x_{1}, x_{2}\right) d x_{2} \text { on } \Sigma
\end{array}\right.
$$


and for a.e. $\left.x_{1} \in\right] 0, c[$

$$
\left\{\begin{array}{l}
\left.\frac{E t^{3}}{12} \frac{1}{l} \frac{\partial^{4} v_{0}}{\partial y_{1}^{4}}\left(x_{1}, y_{1}\right)=\int_{-1}^{0} g\left(x_{1}, x_{2}\right) d x_{2} \text { for } y_{1} \in\right] 0, a[ \\
\left.\frac{E t^{3}}{12} \frac{1}{l} \frac{\partial^{4} v_{0}}{\partial y_{1}^{4}}\left(x_{1}, y_{1}\right)=\int_{-1}^{0} g\left(x_{1}, x_{2}\right) d x_{2} \text { for } y_{1} \in\right] b, 1[ \\
v_{0}\left(x_{1}, a\right)=\frac{\partial v_{0}}{\partial y_{1}}\left(x_{1}, a\right)=v_{0}\left(x_{1}, b\right)=\frac{\partial v_{0}}{\partial y_{1}}\left(x_{1}, b\right)=0 \\
v_{0}\left(x_{1}, 0\right)=v_{0}\left(x_{1}, 1\right), \\
\frac{\partial v_{0}}{\partial y_{1}}\left(x_{1}, 0\right)=\frac{\partial v_{0}}{\partial y_{1}}\left(x_{1}, 1\right), \\
\frac{\partial^{2} v_{0}}{\partial y_{1}^{2}}\left(x_{1}, 0\right)=\frac{\partial^{2} v_{0}}{\partial y_{1}^{2}}\left(x_{1}, 1\right), \\
\frac{\partial^{3} v_{0}}{\partial y_{1}^{3}}\left(x_{1}, 0\right)=\frac{\partial^{3} v_{0}}{\partial y_{1}^{3}}\left(x_{1}, 1\right), \\
\left.v_{0}\left(x_{1}, y_{1}\right)=0 \text { for } y_{1} \in \omega=\right] a, b[
\end{array}\right.
$$

respectively.

The solution of Problem (1.14) can be explicitly computed, by solving a linear system of 8 equations with 8 unknowns. Then, for a.e. $\left.x_{1} \in\right] 0, c[$, it results that

$$
v_{0}\left(x_{1}, y_{1}\right)=\left\{\begin{array}{l}
\frac{l}{2 E t^{3}}\left(a-y_{1}\right)^{2}\left(1-b+y_{1}\right)^{2} \int_{-1}^{0} g\left(x_{1}, x_{2}\right) d x_{2} \text { for } y_{1} \in[0, a[, \\
0 \text { for } y_{1} \in \omega=[a, b], \\
\left.\left.\frac{l}{2 E t^{3}}\left(1+a-y_{1}\right)^{2}\left(b-y_{1}\right)^{2} \int_{-1}^{0} g\left(x_{1}, x_{2}\right) d x_{2} \text { for } y_{1} \in\right] b, 1\right],
\end{array}\right.
$$

and consequently

$$
\begin{aligned}
& \int_{0}^{1} v_{0}\left(x_{1}, y_{1}\right) d y_{1}= \\
& \frac{l}{2 E t^{3}}\left\{\frac{1}{30}+\frac{a}{6}+\frac{a^{2}}{3}+\frac{a^{3}}{3}+\frac{a^{4}}{6}+\frac{a^{5}}{30}-\frac{b}{6}-\frac{2 a b}{3}-a^{2} b-\frac{2 a^{3} b}{3}-\frac{a^{4} b}{6}+\right. \\
& \left.+\frac{b^{2}}{3}+a b^{2}+a^{2} b^{2}+\frac{a^{3} b^{2}}{3}-\frac{b^{3}}{3}-\frac{2 a b^{3}}{3}-\frac{a^{2} b^{3}}{3}+\frac{b^{4}}{6}+\frac{a b^{4}}{6}-\frac{b^{5}}{30}\right\} \int_{-1}^{0} g\left(x_{1}, x_{2}\right) d x_{2} .
\end{aligned}
$$


In the limit domain $\Omega^{+}$of the comb, we obtain a continuum bending model of rods subjected to a force $f$, clamped on the upper side $\Gamma$, and subjected on the lower side $\Sigma$ to applied forces but without applied momentum. The forces on $\Sigma$ depend on the limit density $g$ of the transverse loads on the thin strip $\Omega_{\varepsilon}^{-}$, and on the measure of the cross section $\omega$ of the reference tooth. The force $f$ depends on the limit of the transverse loads on the teeth.

The limit solution meets a Dirichlet transmission condition between $\Omega^{+}$and the rescaled strip $\Omega^{-}$, if $h_{\varepsilon} \gg \varepsilon^{4}$, or if $h_{\varepsilon} \simeq \varepsilon^{4}$ and $\int_{-1}^{0} g\left(x_{1}, x_{2}\right) d x_{2}=0$ a.e. in $] 0, c[$. While, if the strip is thin enough and the transverse loads on the thin strip are strong enough, i.e. $h_{\varepsilon} \simeq \varepsilon^{4}$ and $\int_{-1}^{0} g\left(x_{1}, x_{2}\right) d x_{2} \neq 0$ in a subset of $] 0, c[$ with positive measure, a discontinuity in the Dirichlet transmission condition appears. Roughly speaking, this means that microscopic oscillations of the displacement in the strip, between the basis of the teeth of $\Omega_{\varepsilon}^{+}$, produce a limit average field different from that on the base of the teeth. Point out that (1.15) provides that $\int_{0}^{1} v_{0}\left(x_{1}, y_{1}\right) d y_{1} \neq 0$ in a subset of $] 0, c[$ with positive measure if and only if $\int_{-1}^{0} g\left(x_{1}, x_{2}\right) d x_{2} \neq 0$ in the same subset. Consequently, by taking into account the definition of $g$ in (1.6), for obtaining the additional term in (1.11) when $h_{\varepsilon} \simeq \varepsilon^{4}$, it is necessary that the transverse loads in the thin strip $\Omega_{\varepsilon}^{-}$are strong enough to avoid that $\lim _{\varepsilon \rightarrow 0}\left(h_{\varepsilon} \int_{\Omega_{\varepsilon}^{-}}\left|F_{\varepsilon}\right|^{2} d x\right)=0$. For instance, if $F_{\varepsilon}=\varepsilon^{-4 \alpha}$ in $\Omega_{\varepsilon}^{-}$, the additional term in the displacement of the strip intervenes when $\alpha=1$ and it is given by formula (1.16) with $g=1$, it does not appears when $\alpha<1$.

As regards the Laplacian, in [6] the authors prove that $h_{\varepsilon} \simeq \varepsilon^{2}$ is a critical size for the thickness of the thin domain. In particular, if $h_{\varepsilon} \ll \varepsilon^{2}$, they give an example in which $g=0$ and the sequence $\left\{u_{\left.\varepsilon\right|_{\Omega^{-}}}\right\}_{\varepsilon}$ is not even bounded in $L^{1}\left(\Omega^{-}\right)$. In our paper, as regard the case $h_{\varepsilon} \ll \varepsilon^{4}$, we think that a deterministic limit model may hardly be expected, but we have not an example to validate it.

In what concerns the original Problem (1.3), the result below immediately follows from Theorem 1.1:

Corollary 1.3. Let $U_{\varepsilon}$ be the solution of Problem (1.3), under the assumptions of Theorem 1.1, with $\left\{f_{\varepsilon}\right\}_{\varepsilon}$ defined by (1.4).

Then, it results that

$$
\begin{gathered}
\widetilde{U_{\varepsilon}} \rightarrow|\omega| \text { u weakly in } W^{2}\left(\Omega^{+}\right), \\
\widetilde{\partial_{x_{1}}^{2} U_{\varepsilon}} \rightarrow-\mu|\omega| \partial_{x_{2}}^{2} u \text { weakly in } L^{2}\left(\Omega^{+}\right), \\
\widetilde{\partial_{x_{1} x_{2}}^{2} U_{\varepsilon}} \rightarrow 0 \text { weakly in } L^{2}\left(\Omega^{+}\right), \\
\lim _{\varepsilon \rightarrow 0} \frac{1}{\left|\Omega_{\varepsilon}^{-}\right|} \int_{\Omega_{\varepsilon}^{-}} U_{\varepsilon} d x=\frac{1}{c} \int_{0}^{c}\left(u_{\left.\right|_{\Sigma}}+\int_{0}^{1} v_{0} d y_{1}\right) d x_{1}, \\
\lim _{\varepsilon \rightarrow 0} \frac{1}{\left|\Omega_{\varepsilon}^{-}\right|^{\alpha}} \int_{\Omega_{\varepsilon}^{-}} \partial_{x_{2}} U_{\varepsilon} d x=\lim _{\varepsilon \rightarrow 0} \frac{1}{\left|\Omega_{\varepsilon}^{-}\right|^{\beta}} \int_{\Omega_{\varepsilon}^{-}} \partial_{x_{1} x_{2}}^{2} U_{\varepsilon} d x=\lim _{\varepsilon \rightarrow 0} \frac{1}{\left|\Omega_{\varepsilon}^{-}\right|^{\beta}} \int_{\Omega_{\varepsilon}^{-}} \partial_{x_{2}}^{2} U_{\varepsilon} d x=0, \forall \alpha<\frac{3}{4}, \forall \beta<\frac{1}{2},
\end{gathered}
$$

where $u$ is the weak solution of Problem (1.13), $u_{\left.\right|_{\Sigma}}$ denotes the trace of $u$ on $\Sigma$, and $v_{0}=0$ if $l=0$ in (1.9), while, if $l \in] 0,+\infty\left[, v_{0}\left(=v_{0}\left(x_{1}, y_{1}\right)\right)\right.$ is the solution of Problem (1.14). 
Furthermore, the energies converge in the sense that

$$
\begin{aligned}
& \lim _{\varepsilon \rightarrow 0}\left(\frac{E t^{3}}{12\left(1-\mu^{2}\right)} \int_{\Omega_{\varepsilon}^{+} \cup \Omega_{\varepsilon}^{-}}\left|\Delta U_{\varepsilon}\right|^{2}+2(1-\mu)\left(\left|\partial_{x_{1} x_{2}}^{2} U_{\varepsilon}\right|^{2}-\partial_{x_{1}}^{2} U_{\varepsilon} \partial_{x_{2}}^{2} U_{\varepsilon}\right) d x\right)= \\
& \frac{E t^{3}}{12}\left(|\omega| \int_{\Omega^{+}}\left|\partial_{x_{2}}^{2} u\right|^{2} d x+\frac{1}{l} \int_{] 0, c[\times] 0,1[}\left|\partial_{y_{1}}^{2} v_{0}\left(x_{1}, y_{1}\right)\right|^{2} d x_{1} d y_{1}\right),
\end{aligned}
$$

where $\infty \cdot 0$ means 0 .

For the study of multi-structures, we refer to [8], [10], [18], [19], [24], [25], [27] and the references quoted therein.

Boundary-value problems involving rough boundaries or interfaces appear in many fields of physics and engineering sciences, such as the scattering of acoustic waves on small periodic obstacles, the free vibrations of strongly nonhomogeneous elastic bodies, the behavior of fluids over rough walls, or of coupled fluid-solid periodic structures. For the study of boundary homogenization for highly oscillating boundaries we refer to [2], [3], [4], [5], [6], [7], [11], [12], [14], [15], [17], [20], [21] and [22]. In particular we recall that the asymptotic behavior of a monotone nonlinear second order Neumann problem, with growth $p-1(p \in] 1,+\infty[)$, in an analogous multidomain of $\mathbb{R}^{N}(N \geq 2)$, as considered in this paper, is studied in [5] and [6]. The authors prove that $h_{\varepsilon}=\varepsilon^{p}$ is a critical size for the thickness of the thin domain. Precisely, if $\varepsilon^{p} \ll h_{\varepsilon}$, the limit solution meets a Dirichlet transmission condition between the limit domain of the region with oscillating boundary and the upper side of the rescaled thin domain. If $\varepsilon^{p} \simeq h_{\varepsilon}$, a discontinuity in the Dirichlet transmission condition may occur. While, if $\varepsilon^{p} \gg h_{\varepsilon}$, a deterministic limit model may hardly be expected.

As regards the asymptotic behavior of a fourth order problem in a thin multidomain we refer to [16] and the references quoted therein. In [16] the authors consider a thin multidomain of $\mathbb{R}^{N}(N \geq 2)$ consisting (e.g. in a $3 D$ setting) of a only one vertical rod upon a horizontal disk. In this thin multidomain they introduce a bulk energy density of the kind $W\left(D^{2} U\right)$, where $W$ is a convex function with growth $\left.p \in\right] 1,+\infty[$. By assuming that the two volumes tend to zero with same rate, under suitable boundary conditions, they show that the limit problem (well posed in the union of the limit domains) is uncoupled if $1<p \leq \frac{N-1}{2}$, "partially" coupled if $\frac{N-1}{2}<p \leq N-1$, and coupled if $N-1<p$.

Our paper is organized as follows: in Section 2, by making use of some results in [5], some a priori norm-estimates for the solution of Problem (1.5) are obtained. In Section 3, these estimates provide some convergence results in $L^{2}$-norm, in the weak topology of $L^{2}$, or in the setting of the two-scale convergence method, proposed by G. Nguetseng in [23] and developed by G. Allaire in [1]. Finally, in Section 4, the limit problem is derived by making use of the method of oscillating test functions, introduced by L. Tartar in [26].

\section{$2 \quad$ A priori norm-estimates}

Define

$$
D^{2}(v)=\left(\begin{array}{cc}
\partial_{x_{1}}^{2} v & \partial_{x_{1} x_{2}}^{2} v \\
\partial_{x_{1} x_{2}}^{2} v & \partial_{x_{2}}^{2} v
\end{array}\right), \quad v \in H^{2}\left(\Omega_{\varepsilon}^{+}\right)
$$




$$
D_{\varepsilon}^{2}(v)=\left(\begin{array}{cc}
\partial_{x_{1}}^{2} v & \frac{1}{h_{\varepsilon}} \partial_{x_{1} x_{2}}^{2} v \\
\frac{1}{h_{\varepsilon}} \partial_{x_{1} x_{2}}^{2} v & \frac{1}{h_{\varepsilon}^{2}} \partial_{x_{2}}^{2} v
\end{array}\right), \quad v \in H^{2}\left(\Omega^{-}\right)
$$

for every $\varepsilon$. This section is devoted to prove the following a priori norm-estimates:

Proposition 2.1. Let $u_{\varepsilon}$ be the solution of Problem (1.5). Assume (1.9) and (1.6). Then, there exists a constant $c$ such that

$$
\begin{gathered}
\left\|u_{\varepsilon}\right\|_{H^{2}\left(\Omega_{\varepsilon}^{+}\right)} \leq c, \\
\left\|h_{\varepsilon}^{\frac{1}{2}} D_{\varepsilon}^{2}\left(u_{\varepsilon}\right)\right\|_{\left(L^{2}\left(\Omega^{-}\right)\right)^{4}} \leq c,
\end{gathered}
$$

for every $\varepsilon$.

To prove Proposition 2.1, the following result is required.

Lemma 2.2. There exists a constant $c$ such that

$$
\begin{gathered}
\|v\|_{L^{2}\left(\Omega^{-}\right)}^{2} \leq c\left(\|v\|_{L^{2}\left(\Sigma \backslash \partial \Omega_{\varepsilon}\right)}^{2}+\varepsilon^{2}\left\|\partial_{x_{1}} v\right\|_{L^{2}\left(\Omega^{-}\right)}^{2}+\left\|\partial_{x_{2}} v\right\|_{L^{2}\left(\Omega^{-}\right)}^{2}\right), \quad \forall v \in H^{1}\left(\Omega^{-}\right) \\
\|v\|_{L^{2}\left(\Sigma \backslash \partial \Omega_{\varepsilon}\right)}^{2} \leq c\left(\|v\|_{L^{2}\left(\Omega_{\varepsilon}^{+}\right)}^{2}+\left\|\partial_{x_{2}} v\right\|_{L^{2}\left(\Omega_{\varepsilon}^{+}\right)}^{2}\right), \quad \forall v \in H^{1}\left(\Omega_{\varepsilon}^{+}\right) ; \\
\|v\|_{H^{2}\left(\Omega_{\varepsilon}^{+}\right)}^{2} \leq c\left\|D^{2} v\right\|_{\left(L^{2}\left(\Omega_{\varepsilon}^{+}\right)\right)^{4}}^{2}, \quad \forall v \in\left\{v \in H^{2}\left(\Omega_{\varepsilon}^{+}\right): v=0, \text { Dv }=0 \text { on } \Gamma_{\varepsilon}\right\}
\end{gathered}
$$

for every $\varepsilon$.

Proof. The proof of inequality (2.3) is performed in the proof of Proposition 3.3 in [5]. Easy computations give inequalities (2.4) and (2.5).

Proof of Proposition 2.1. In the sequel, $c$ denotes any positive constant independent of $\varepsilon$.

By choosing $v=u_{\varepsilon}$ in (1.5), it results that

$$
\begin{aligned}
& M \int_{\Omega_{\varepsilon}^{+}}\left|\partial_{x_{1}}^{2} u_{\varepsilon}\right|^{2}+\left|\partial_{x_{2}}^{2} u_{\varepsilon}\right|^{2}+2 \mu \partial_{x_{1}}^{2} u_{\varepsilon} \partial_{x_{2}}^{2} u_{\varepsilon}+2(1-\mu)\left|\partial_{x_{1} x_{2}}^{2} u_{\varepsilon}\right|^{2} d x+ \\
& +M h_{\varepsilon} \int_{\Omega^{-}}\left|\partial_{x_{1}}^{2} u_{\varepsilon}\right|^{2}+\left|\frac{1}{h_{\varepsilon}^{2}} \partial_{x_{2}}^{2} u_{\varepsilon}\right|^{2}+2 \mu \partial_{x_{1}}^{2} u_{\varepsilon} \frac{1}{h_{\varepsilon}^{2}} \partial_{x_{2}}^{2} u_{\varepsilon}+2(1-\mu)\left|\frac{1}{h_{\varepsilon}} \partial_{x_{1} x_{2}}^{2} u_{\varepsilon}\right|^{2} d x= \\
& =\int_{\Omega_{\varepsilon}^{+}} f_{\varepsilon} u_{\varepsilon} d x+h_{\varepsilon} \int_{\Omega^{-}} f_{\varepsilon} u_{\varepsilon} d x,
\end{aligned}
$$

for every $\varepsilon$. Consequently, by taking into account that $-\alpha^{2}-\beta^{2} \leq 2 \alpha \beta$, for $\alpha, \beta \in \mathbb{R}$, and by making use of assumption (1.6), one obtains that

$$
\begin{aligned}
& \int_{\Omega_{\varepsilon}^{+}}\left|\partial_{x_{1}}^{2} u_{\varepsilon}\right|^{2}+\left|\partial_{x_{2}}^{2} u_{\varepsilon}\right|^{2}-\mu\left|\partial_{x_{1}}^{2} u_{\varepsilon}\right|^{2}-\mu\left|\partial_{x_{2}}^{2} u_{\varepsilon}\right|^{2}+2(1-\mu)\left|\partial_{x_{1} x_{2}}^{2} u_{\varepsilon}\right|^{2} d x+ \\
& +h_{\varepsilon} \int_{\Omega^{-}}\left|\partial_{x_{1}}^{2} u_{\varepsilon}\right|^{2}+\left|\frac{1}{h_{\varepsilon}^{2}} \partial_{x_{2}}^{2} u_{\varepsilon}\right|^{2}-\mu\left|\partial_{x_{1}}^{2} u_{\varepsilon}\right|^{2}-\mu\left|\frac{1}{h_{\varepsilon}^{2}} \partial_{x_{2}}^{2} u_{\varepsilon}\right|^{2}+2(1-\mu)\left|\frac{1}{h_{\varepsilon}} \partial_{x_{1} x_{2}}^{2} u_{\varepsilon}\right|^{2} d x \leq \\
& \leq c\left(\left\|u_{\varepsilon}\right\|_{L^{2}\left(\Omega_{\varepsilon}^{+}\right)}+\left\|u_{\varepsilon}\right\|_{L^{2}\left(\Omega^{-}\right)}\right),
\end{aligned}
$$


for every $\varepsilon$, that is

$$
\left\|D^{2} u_{\varepsilon}\right\|_{\left(L^{2}\left(\Omega_{\varepsilon}^{+}\right)\right)^{4}}^{2}+h_{\varepsilon}\left\|D_{\varepsilon}^{2} u_{\varepsilon}\right\|_{\left(L^{2}\left(\Omega^{-}\right)\right)^{4}}^{2} \leq c\left(\left\|u_{\varepsilon}\right\|_{L^{2}\left(\Omega_{\varepsilon}^{+}\right)}+\left\|u_{\varepsilon}\right\|_{L^{2}\left(\Omega^{-}\right)}\right),
$$

for every $\varepsilon$.

On the other hand, by applying (2.3) three times and by recalling that $\partial_{x_{2}} u_{\varepsilon}^{-}=h_{\varepsilon} \partial_{x_{2}} u_{\varepsilon}^{+}$ on $\Sigma \backslash \partial \Omega_{\varepsilon}$, one obtains that

$$
\begin{aligned}
& \left\|u_{\varepsilon}\right\|_{L^{2}\left(\Omega^{-}\right)}^{2} \leq c\left(\left\|u_{\varepsilon}\right\|_{L^{2}\left(\Sigma \backslash \partial \Omega_{\varepsilon}\right)}^{2}+\varepsilon^{2}\left\|\partial_{x_{1}} u_{\varepsilon}\right\|_{L^{2}\left(\Omega^{-}\right)}^{2}+\left\|\partial_{x_{2}} u_{\varepsilon}\right\|_{L^{2}\left(\Omega^{-}\right)}^{2}\right) \leq \\
& \leq c\left\|u_{\varepsilon}\right\|_{L^{2}\left(\Sigma \backslash \partial \Omega_{\varepsilon}\right)}^{2}+ \\
& +c \varepsilon^{2}\left(\left\|\partial_{x_{1}} u_{\varepsilon}\right\|_{L^{2}\left(\Sigma \backslash \partial \Omega_{\varepsilon}\right)}^{2}+\varepsilon^{2}\left\|\partial_{x_{1}}^{2} u_{\varepsilon}\right\|_{L^{2}\left(\Omega^{-}\right)}^{2}+\left\|\partial_{x_{1} x_{2}}^{2} u_{\varepsilon}\right\|_{L^{2}\left(\Omega^{-}\right)}^{2}\right)+ \\
& +c\left(\left\|\partial_{x_{2}} u_{\varepsilon}^{-}\right\|_{L^{2}\left(\Sigma \backslash \partial \Omega_{\varepsilon}\right)}^{2}+\varepsilon^{2}\left\|\partial_{x_{1} x_{2}}^{2} u_{\varepsilon}\right\|_{L^{2}\left(\Omega^{-}\right)}^{2}+\left\|\partial_{x_{2}}^{2} u_{\varepsilon}\right\|_{L^{2}\left(\Omega^{-}\right)}^{2}\right)= \\
& =c\left(\left\|u_{\varepsilon}\right\|_{L^{2}\left(\Sigma \backslash \partial \Omega_{\varepsilon}\right)}^{2}+\varepsilon^{2}\left\|\partial_{x_{1}} u_{\varepsilon}\right\|_{L^{2}\left(\Sigma \backslash \partial \Omega_{\varepsilon}\right)}^{2}+\left\|h_{\varepsilon} \partial_{x_{2}} u_{\varepsilon}^{+}\right\|_{L^{2}\left(\Sigma \backslash \partial \Omega_{\varepsilon}\right)}^{2}\right)+ \\
& +c\left(\varepsilon^{4}\left\|\partial_{x_{1}}^{2} u_{\varepsilon}\right\|_{L^{2}\left(\Omega^{-}\right)}^{2}+\varepsilon^{2}\left\|\partial_{x_{1} x_{2}}^{2} u_{\varepsilon}\right\|_{L^{2}\left(\Omega^{-}\right)}^{2}+\left\|\partial_{x_{2}}^{2} u_{\varepsilon}\right\|_{L^{2}\left(\Omega^{-}\right)}^{2}\right),
\end{aligned}
$$

for every $\varepsilon$, from which, by virtue of (2.4), it follows that

$$
\begin{aligned}
& \left\|u_{\varepsilon}\right\|_{L^{2}\left(\Omega^{-}\right)}^{2} \leq c\left\|u_{\varepsilon}\right\|_{H^{2}\left(\Omega_{\varepsilon}^{+}\right)}^{2}+ \\
& +\operatorname{ch}_{\varepsilon}\left(\frac{\varepsilon^{4}}{h_{\varepsilon}}\left\|\partial_{x_{1}}^{2} u_{\varepsilon}\right\|_{L^{2}\left(\Omega^{-}\right)}^{2}+\left\|\frac{1}{h_{\varepsilon}} \partial_{x_{1} x_{2}}^{2} u_{\varepsilon}\right\|_{L^{2}\left(\Omega^{-}\right)}^{2}+\left\|\frac{1}{h_{\varepsilon}^{2}} \partial_{x_{2}}^{2} u_{\varepsilon}\right\|_{L^{2}\left(\Omega^{-}\right)}^{2}\right)
\end{aligned}
$$

for every $\varepsilon$.

By combining (2.6) with (2.7), by making use of (2.5) and by assuming that the limit (1.9) is finite, one has that

$$
\left\|u_{\varepsilon}\right\|_{H^{2}\left(\Omega_{\varepsilon}^{+}\right)}^{2}+h_{\varepsilon}\left\|D_{\varepsilon}^{2} u_{\varepsilon}\right\|_{\left(L^{2}\left(\Omega^{-}\right)\right)^{4}}^{2} \leq c\left(\left\|u_{\varepsilon}\right\|_{H^{2}\left(\Omega_{\varepsilon}^{+}\right)}^{2}+h_{\varepsilon}\left\|D_{\varepsilon}^{2} u_{\varepsilon}\right\|_{\left(L^{2}\left(\Omega^{-}\right)\right)^{4}}^{2}\right)^{\frac{1}{2}}
$$

for every $\varepsilon$, which provides estimates (2.1) and (2.2).

Corollary 2.3. Let $u_{\varepsilon}$ be the solution of Problem (1.5). Assume (1.9) and (1.6). Then, there exists a constant $c$ such that

$$
\begin{gathered}
\left\|\varepsilon^{2} \partial_{x_{1}}^{2} u_{\varepsilon}\right\|_{L^{2}\left(\Omega^{-}\right)} \leq c \\
\left\|\frac{1}{h_{\varepsilon}^{\frac{1}{2}}} \partial_{x_{1} x_{2}}^{2} u_{\varepsilon}\right\|_{L^{2}\left(\Omega^{-}\right)} \leq c
\end{gathered}
$$




$$
\begin{gathered}
\left\|\frac{1}{h_{\varepsilon}^{\frac{3}{2}}} \partial_{x_{2}}^{2} u_{\varepsilon}\right\|_{L^{2}\left(\Omega^{-}\right)} \leq c, \\
\left\|\frac{1}{h_{\varepsilon}^{\frac{3}{4}}} \partial_{x_{2}} u_{\varepsilon}\right\|_{L^{2}\left(\Omega^{-}\right)} \leq c, \\
\left\|\varepsilon \partial_{x_{1}} u_{\varepsilon}\right\|_{L^{2}\left(\Omega^{-}\right)} \leq c \\
\left\|u_{\varepsilon}\right\|_{L^{2}\left(\Omega^{-}\right)} \leq c,
\end{gathered}
$$

for every $\varepsilon$.

Proof. Estimates (2.8), (2.9) and (2.10) follow immediately from estimate (2.2). By combining estimate (2.2) with inequalities (2.3) and (2.4), and by recalling that $\partial_{x_{2}} u_{\varepsilon}^{-}=h_{\varepsilon} \partial_{x_{2}} u_{\varepsilon}^{+}$ on $\Sigma \backslash \partial \Omega_{\varepsilon}$, it is easy to obtain (2.11), (2.12) and (2.13).

\section{Convergence results}

The a priori norm-estimates of the solution $u_{\varepsilon}$ of Problem (1.5) provide the following convergence result:

Proposition 3.1. Let $u_{\varepsilon}$ be the solution of Problem (1.5). Let $W^{2}\left(\Omega^{+}\right)$be the space defined in (1.7). Assume (1.6) and (1.9). Then,

$$
\begin{gathered}
\left\|\partial_{x_{2}} u_{\varepsilon}\right\|_{L^{2}\left(\Omega^{-}\right)} \leq c h_{\varepsilon}^{\frac{3}{4}}, \\
\left\|\partial_{x_{1} x_{2}}^{2} u_{\varepsilon}\right\|_{L^{2}\left(\Omega^{-}\right)} \leq c h_{\varepsilon}^{\frac{1}{2}}, \quad\left\|\partial_{x_{2}}^{2} u_{\varepsilon}\right\|_{L^{2}\left(\Omega^{-}\right)} \leq c h_{\varepsilon}^{\frac{3}{2}},
\end{gathered}
$$

for every $\varepsilon$, where $c$ is a constant independent of $\varepsilon$. Moreover, there exist a subsequence of $\{\varepsilon\}$, still denoted by $\{\varepsilon\}, u \in W^{2}\left(\Omega^{+}\right), \eta, \zeta \in L^{2}\left(\Omega^{+}\right), u_{0}\left(=u_{0}\left(x_{1}, y_{1}\right)\right) \in L^{2}(] 0, c\left[, H_{p e r}^{2}(] 0,1[)\right)$ and $\xi\left(=\xi\left(\left(x_{1}, x_{2}\right),\left(y_{1}, y_{2}\right)\right)\right) \in L^{2}\left(\Omega^{-} \times\right] 0,1\left[^{2}\right)$ such that

$$
\begin{gathered}
\widetilde{u_{\varepsilon}} \rightarrow|\omega| \text { u weakly in } W^{2}\left(\Omega^{+}\right), \\
\widetilde{\partial_{x_{1}}^{2} u_{\varepsilon}} \rightarrow \eta \text { weakly in } L^{2}\left(\Omega^{+}\right), \\
\left\{\partial_{x_{1} x_{2}}^{2} u_{\varepsilon}\right. \\
\left\{u_{\varepsilon}^{-}\right\}_{\varepsilon} \text { two-scale converges to } u_{0}, \\
\left\{\varepsilon \partial_{x_{1}} u_{\varepsilon}^{-}\right\}_{\varepsilon} \text { two-scale converges to } \partial_{y_{1}} u_{0}, \\
\left\{\varepsilon^{2} \partial_{x_{1}}^{2} u_{\varepsilon}^{-}\right\}_{\varepsilon} \text { two-scale converges to } \partial_{y_{1}}^{2} u_{0}, \\
\left\{\frac{1}{h_{\varepsilon}^{\frac{3}{2}}} \partial_{x_{2}}^{2} u_{\varepsilon}^{-}\right\}_{\varepsilon} \text { two-scale converges to } \xi,
\end{gathered}
$$

as $\varepsilon \rightarrow 0$, and

$$
\left.u_{0}\left(x_{1}, y_{1}\right)=u_{\left.\right|_{\Sigma}}\left(x_{1}, 0\right) \text { in }\right] 0, c[\times \omega
$$


Proof. Estimates (3.1) and (3.2) follow from estimates (2.11), (2.9) and (2.10). Convergences (3.3), (3.4) and (3.5) are a consequence of estimate (2.1). Estimates (2.13), (2.12), (2.8), (3.1) and (3.2) provide convergences (3.6), (3.7) and (3.8) with $u_{0} \in L^{2}\left(\Omega^{-}, H_{\text {per }}^{2}(] 0,1[)\right)$. Moreover, $u_{0}$ is independent of $x_{2}$, too. In fact, it results that

$$
\begin{aligned}
& 0=\lim _{\varepsilon \rightarrow 0} \int_{\Omega^{-}} \partial_{x_{2}} u_{\varepsilon} \varphi\left(x, \frac{x_{1}}{\varepsilon}\right) d x=-\lim _{\varepsilon \rightarrow 0} \int_{\Omega^{-}} u_{\varepsilon} \partial_{x_{2}} \varphi\left(x, \frac{x_{1}}{\varepsilon}\right) d x= \\
& -\int_{\left.\Omega^{-} \times\right] 0,1[} u_{0}\left(x, y_{1}\right) \partial_{x_{2}} \varphi\left(x, y_{1}\right) d x d y_{1}, \quad \forall \varphi \in C_{0}^{\infty}\left(\Omega^{-} \times\right] 0,1[) .
\end{aligned}
$$

Convergence (3.9) springs from estimate (2.10). Statement (3.10) can be obtained by arguing as in the proof of (6.6) in Proposition 6.4 of [6].

If $l=0$ in (1.9), then $u_{0}$ can be completely identified in terms of $u$ :

Corollary 3.2. Let $u_{\varepsilon}$ be the solution of Problem (1.5). Assume (1.9) with $l=0$, and (1.6). Let $u \in W^{2}\left(\Omega^{+}\right)$and $u_{0} \in L^{2}(] 0, c\left[, H_{\text {per }}^{2}(] 0,1[)\right)$ be satisfying Proposition 3.1. Then,

$$
\left.u_{0}\left(x_{1}, y_{1}\right)=u_{\left.\right|_{\Sigma}}\left(x_{1}, 0\right) \text { in }\right] 0, c[\times] 0,1[\text {. }
$$

Proof. Assumption (1.9) with $l=0$ and estimate (2.2) ensure that

$$
\varepsilon^{2} \partial_{x_{1}}^{2} u_{\varepsilon} \rightarrow 0 \text { strongly in } L^{2}\left(\Omega^{-}\right),
$$

as $\varepsilon \rightarrow 0$. Consequently, by virtue of (3.8), it results that

$$
\left.\partial_{y_{1}}^{2} u_{0}=0 \text { in }\right] 0, c[\times] 0,1[.
$$

By combining (3.10) with (3.12), one obtains (3.11).

\section{The limit problem}

The following proposition is devoted to identify the limit problem in $\Omega^{+}$.

Proposition 4.1. Let $u_{\varepsilon}$ be the solution of Problem (1.5). Assume (1.9) and (1.6). Let $u \in W^{2}\left(\Omega^{+}\right)$and $\eta, \zeta \in L^{2}\left(\Omega^{+}\right)$be satisfying Proposition 3.1. Then,

$$
\begin{gathered}
\eta=-\mu|\omega| \partial_{x_{2}}^{2} \text { u a.e. in } \Omega^{+}, \\
\zeta=0 \text { a.e. in } \Omega^{+},
\end{gathered}
$$

and $u \in W^{2}\left(\Omega^{+}\right)$is the unique solution of

$$
\begin{aligned}
& M|\omega|\left(1-\mu^{2}\right) \int_{\Omega^{+}} \partial_{x_{2}}^{2} u \partial_{x_{2}}^{2} v d x=|\omega| \int_{\Omega^{+}} f v d x+ \\
& +\int_{0}^{c}\left(\int_{-1}^{0} g\left(x_{1}, x_{2}\right) d x_{2}\right) v\left(x_{1}, 0\right) d x_{1} \quad \forall v \in W^{2}\left(\Omega^{+}\right),
\end{aligned}
$$

where $\mu \in] 0, \frac{1}{2}[$ is the Poisson ratio, $M>0$ represents the flexural rigidity modulus of the plate (see Problem (1.5)), and $f, g \in L^{2}\left(\Omega^{-}\right)$are given by (1.6). 
Proof. At first, claim (4.1) will be proved. To this aim, choose $v=\varepsilon^{2} \psi_{1}\left(\frac{x_{1}}{\varepsilon}\right) \varphi\left(x_{1}, x_{2}\right)$ as test function in (1.5), where $\psi_{1}$ is the 1 -periodic function defined by $\psi_{1}\left(y_{1}\right)=\frac{1}{2} y_{1}\left(y_{1}-1\right)$ in $[0,1]$ and $\varphi \in C_{0}^{\infty}\left(\Omega^{+}\right)$(point out that $\left.v \in C^{\infty}\left(\overline{\Omega_{\varepsilon}^{+}}\right) \cap C_{0}\left(\Omega^{+}\right) \subset V_{\varepsilon}\right)$. Then, it results that

$$
\begin{aligned}
& M \int_{\Omega_{\varepsilon}^{+}} \Delta u_{\varepsilon}\left(\varphi+2 \varepsilon \psi_{1}^{\prime}\left(\frac{x_{1}}{\varepsilon}\right) \partial_{x_{1}} \varphi+\varepsilon^{2} \psi_{1}\left(\frac{x_{1}}{\varepsilon}\right) \partial_{x_{1}}^{2} \varphi+\varepsilon^{2} \psi_{1}\left(\frac{x_{1}}{\varepsilon}\right) \partial_{x_{2}}^{2} \varphi\right) d x+ \\
& +M(1-\mu) \int_{\Omega_{\varepsilon}^{+}} 2 \partial_{x_{1} x_{2}}^{2} u_{\varepsilon}\left(\varepsilon \psi_{1}^{\prime}\left(\frac{x_{1}}{\varepsilon}\right) \partial_{x_{2}} \varphi+\varepsilon^{2} \psi_{1}\left(\frac{x_{1}}{\varepsilon}\right) \partial_{x_{1} x_{2}}^{2} \varphi\right) d x+ \\
& -M(1-\mu) \int_{\Omega_{\varepsilon}^{+}} \partial_{x_{1}}^{2} u_{\varepsilon} \varepsilon^{2} \psi_{1}\left(\frac{x_{1}}{\varepsilon}\right) \partial_{x_{2}}^{2} \varphi d x+ \\
& -M(1-\mu) \int_{\Omega_{\varepsilon}^{+}} \partial_{x_{2}}^{2} u_{\varepsilon}\left(\varphi+2 \varepsilon \psi_{1}^{\prime}\left(\frac{x_{1}}{\varepsilon}\right) \partial_{x_{1}} \varphi+\varepsilon^{2} \psi_{1}\left(\frac{x_{1}}{\varepsilon}\right) \partial_{x_{1}}^{2} \varphi\right) d x+ \\
& =\int_{\Omega_{\varepsilon}^{+}} f_{\varepsilon} \varepsilon^{2} \psi_{1}\left(\frac{x_{1}}{\varepsilon}\right) \varphi d x
\end{aligned}
$$

for every $\varepsilon$. By passing to the limit, as $\varepsilon \rightarrow 0$, in (4.4) and by making use of (3.3), (3.4), (3.5) and (1.6), it is easy seen that

$$
\int_{\Omega^{+}} \eta \varphi+\mu|\omega| \partial_{x_{2}}^{2} u \varphi d x=0 \quad \forall \varphi \in C_{0}^{\infty}\left(\Omega^{+}\right)
$$

which provides (4.1).

In the next step, it will be proved that the function $\zeta \in L^{2}\left(\Omega^{+}\right)$is independent of $x_{2}$. To this aim, choose $v=\varepsilon \psi_{2}\left(\frac{x_{1}}{\varepsilon}\right) \varphi\left(x_{1}, x_{2}\right)$ as test function in (1.5), where $\psi_{2}$ is the 1-periodic function defined by $\psi_{2}\left(y_{1}\right)=-y_{1}+\frac{1}{2}$ in $\left[0,1\left[\right.\right.$ and $\varphi \in C_{0}^{\infty}\left(\Omega^{+}\right)$(point out that $v \in C^{\infty}\left(\overline{\Omega_{\varepsilon}^{+}}\right)$ and supp $v \subset \Omega^{+}$, consequently $v \in V_{\varepsilon}$ ). Then, it results that

$$
\begin{aligned}
& M \int_{\Omega_{\varepsilon}^{+}} \Delta u_{\varepsilon}\left(-2 \partial_{x_{1}} \varphi+\varepsilon \psi_{2}\left(\frac{x_{1}}{\varepsilon}\right) \partial_{x_{1}}^{2} \varphi+\varepsilon \psi_{2}\left(\frac{x_{1}}{\varepsilon}\right) \partial_{x_{2}}^{2} \varphi\right) d x+ \\
& +M(1-\mu) \int_{\Omega_{\varepsilon}^{+}} 2 \partial_{x_{1} x_{2}}^{2} u_{\varepsilon}\left(-\partial_{x_{2}} \varphi+\varepsilon \psi_{2}\left(\frac{x_{1}}{\varepsilon}\right) \partial_{x_{1} x_{2}}^{2} \varphi\right) d x+ \\
& -M(1-\mu) \int_{\Omega_{\varepsilon}^{+}} \partial_{x_{1}}^{2} u_{\varepsilon} \varepsilon \psi_{2}\left(\frac{x_{1}}{\varepsilon}\right) \partial_{x_{2}}^{2} \varphi d x+ \\
& -M(1-\mu) \int_{\Omega_{\varepsilon}^{+}} \partial_{x_{2}}^{2} u_{\varepsilon}\left(-2 \partial_{x_{1}} \varphi+\varepsilon \psi_{2}\left(\frac{x_{1}}{\varepsilon}\right) \partial_{x_{1}}^{2} \varphi\right) d x+ \\
& =\int_{\Omega_{\varepsilon}^{+}} f_{\varepsilon} \varepsilon \psi_{2}\left(\frac{x_{1}}{\varepsilon}\right) \varphi d x,
\end{aligned}
$$


for every $\varepsilon$. By passing to the limit, as $\varepsilon \rightarrow 0$, in (4.5) and by making use of (3.3), (3.4), (3.5), (1.6) and (4.1), it is easy seen that

$$
\int_{\Omega^{+}} 2 \mu|\omega| \partial_{x_{2}}^{2} u \partial_{x_{1}} \varphi-2 \mu|\omega| \partial_{x_{2}}^{2} u \partial_{x_{1}} \varphi-2(1-\mu) \zeta \partial_{x_{2}} \varphi d x=0 \quad \forall \varphi \in C_{0}^{\infty}\left(\Omega^{+}\right),
$$

that is

$$
\int_{\Omega^{+}} \zeta \partial_{x_{2}} \varphi d x=0 \quad \forall \varphi \in C_{0}^{\infty}\left(\Omega^{+}\right)
$$

which provides that $\zeta$ is independent of $x_{2}$.

In the third step, claim (4.2) will be proved. To this aim, choose

$$
v=\left\{\begin{array}{l}
\varepsilon \psi_{2}\left(\frac{x_{1}}{\varepsilon}\right) \phi\left(x_{2}\right) \varphi\left(x_{1}\right) \text { in } \Omega_{\varepsilon}^{+}, \\
\varepsilon \psi_{2}\left(\frac{x_{1}}{\varepsilon}\right) \varphi\left(x_{1}\right) \text { in } \Omega^{-},
\end{array}\right.
$$

as test function in (1.5), where $\psi_{2}$ is defined as above, $\phi \in C^{\infty}([0, d])$ is such that $\phi=1$ in $\left[0, \frac{d}{4}\right], \phi=0$ in $\left[\frac{3 d}{4}, d\right]$, and $\varphi \in C_{0}^{\infty}(] 0, c[)$ (it is evident that $v \in V_{\varepsilon}$ ). Then, it results that

$$
\begin{aligned}
& M \int_{\Omega_{\varepsilon}^{+}} \Delta u_{\varepsilon}\left(-2 \phi \partial_{x_{1}} \varphi+\varepsilon \psi_{2}\left(\frac{x_{1}}{\varepsilon}\right) \phi \partial_{x_{1}}^{2} \varphi+\varepsilon \psi_{2}\left(\frac{x_{1}}{\varepsilon}\right) \varphi \partial_{x_{2}}^{2} \phi\right) d x+ \\
& +M(1-\mu) \int_{\Omega_{\varepsilon}^{+}} 2 \partial_{x_{1} x_{2}}^{2} u_{\varepsilon}\left(-\varphi \partial_{x_{2}} \phi+\varepsilon \psi_{2}\left(\frac{x_{1}}{\varepsilon}\right) \partial_{x_{1}} \varphi \partial_{x_{2}} \phi\right) d x+ \\
& -M(1-\mu) \int_{\Omega_{\varepsilon}^{+}} \partial_{x_{1}}^{2} u_{\varepsilon} \varepsilon \psi_{2}\left(\frac{x_{1}}{\varepsilon}\right) \varphi \partial_{x_{2}}^{2} \phi d x+ \\
& -M(1-\mu) \int_{\Omega_{\varepsilon}^{+}} \partial_{x_{2}}^{2} u_{\varepsilon}\left(-2 \phi \partial_{x_{1}} \varphi+\varepsilon \psi_{2}\left(\frac{x_{1}}{\varepsilon}\right) \phi \partial_{x_{1}}^{2} \varphi\right) d x+ \\
& +M h_{\varepsilon}^{\frac{1}{2}} \int_{\Omega^{-}} h_{\varepsilon}^{\frac{1}{2}} \partial_{x_{1}}^{2} u_{\varepsilon}\left(-2 \partial_{x_{1}} \varphi+\varepsilon \psi_{2}\left(\frac{x_{1}}{\varepsilon}\right) \partial_{x_{1}}^{2} \varphi\right) d x+ \\
& +M h_{\varepsilon}^{\frac{1}{2}} \int_{\Omega^{-}} \mu \frac{1}{h_{\varepsilon}^{\frac{3}{2}}} \partial_{x_{2}}^{2} u_{\varepsilon}\left(-2 \partial_{x_{1}} \varphi+\varepsilon \psi_{2}\left(\frac{x_{1}}{\varepsilon}\right) \partial_{x_{1}}^{2} \varphi\right) d x \\
& =\int_{\Omega_{\varepsilon}^{+}} f_{\varepsilon} \varepsilon \psi_{2}\left(\frac{x_{1}}{\varepsilon}\right) \phi \varphi d x+\int_{\Omega^{-}} h_{\varepsilon} f_{\varepsilon} \varepsilon \psi_{2}\left(\frac{x_{1}}{\varepsilon}\right) \varphi d x
\end{aligned}
$$

for every $\varepsilon$. By passing to the limit, as $\varepsilon \rightarrow 0$, in (4.6) and by making use of (3.3), (3.4), (3.5), (4.1), (2.2) and (1.6), it is easy seen that

$$
\int_{\Omega^{+}} \zeta \varphi \partial_{x_{2}} \phi d x=0 \quad \forall \varphi \in C_{0}^{\infty}(] 0, c[),
$$


from which, by recalling the assumptions on $\phi$ and that $\zeta$ is independent of $x_{2}$, it follows that

$$
\int_{0}^{c} \zeta\left(x_{1}\right) \varphi\left(x_{1}\right) d x=0 \quad \forall \varphi \in C_{0}^{\infty}(] 0, c[)
$$

that is (4.2).

Now, the limit problem satisfied by $u$ will be identified. To this aim, choose

$$
v=\left\{\begin{array}{l}
\varphi \text { in } \Omega_{\varepsilon}^{+}, \\
\varphi\left(x_{1}, 0\right)+h_{\varepsilon} x_{2}\left(\partial_{x_{2}} \varphi\right)\left(x^{\prime}, 0\right) \text { in } \Omega^{-},
\end{array}\right.
$$

as test function in (1.5), where $\varphi \in C^{\infty}\left(\overline{\Omega^{+}}\right)$, and $\varphi=0, D \varphi=0$ on $\Gamma$. Then, it results that

$$
\begin{aligned}
& M \int_{\Omega_{\varepsilon}^{+}} \Delta u_{\varepsilon} \Delta \varphi+(1-\mu)\left(2 \partial_{x_{1} x_{2}}^{2} u_{\varepsilon} \partial_{x_{1} x_{2}}^{2} \varphi-\partial_{x_{1}}^{2} u_{\varepsilon} \partial_{x_{2}}^{2} \varphi-\partial_{x_{2}}^{2} u_{\varepsilon} \partial_{x_{1}}^{2} \varphi\right) d x+ \\
& +M h_{\varepsilon}^{\frac{1}{2}} \int_{\Omega^{-}}\left(h_{\varepsilon}^{\frac{1}{2}} \partial_{x_{1}}^{2} u_{\varepsilon}+\frac{1}{h_{\varepsilon}^{\frac{3}{2}}} \partial_{x_{2}}^{2} u_{\varepsilon}\right)\left(\left(\partial_{x_{1}}^{2} \varphi\right)\left(x_{1}, 0\right)+h_{\varepsilon} x_{2}\left(\partial_{x_{1}^{2} x_{2}}^{3} \varphi\right)\left(x_{1}, 0\right)\right) d x+ \\
& +M(1-\mu) \int_{\Omega^{-}} 2 \partial_{x_{1} x_{2}}^{2} u_{\varepsilon}\left(\partial_{x_{2} x_{1}}^{2} \varphi\right)\left(x_{1}, 0\right) d x+ \\
& -M(1-\mu) h_{\varepsilon}^{\frac{1}{2}} \int_{\Omega^{-}} \frac{1}{h_{\varepsilon}^{\frac{3}{2}}} \partial_{x_{2}}^{2} u_{\varepsilon}\left(\left(\partial_{x_{1}}^{2} \varphi\right)\left(x_{1}, 0\right)+h_{\varepsilon} x_{2}\left(\partial_{x_{1}^{2} x_{2}}^{3} \varphi\right)\left(x_{1}, 0\right)\right) d x= \\
& =\int_{\Omega_{\varepsilon}^{+}} f_{\varepsilon} \varphi d x+h_{\varepsilon} \int_{\Omega^{-}} f_{\varepsilon}\left(\varphi\left(x_{1}, 0\right)+h_{\varepsilon} x_{2}\left(\partial_{x_{2}} \varphi\right)\left(x^{\prime}, 0\right)\right) d x,
\end{aligned}
$$

for every $\varepsilon$. By passing to the limit, as $\varepsilon \rightarrow 0$, in (4.7), by making use of (3.3), (3.4), (3.5), (4.1), (4.2), (2.2) and (1.6), and by recalling that

$$
\chi_{\Omega_{\varepsilon}^{+}} \rightarrow|\omega| \text { weakly in } L^{2}\left(\Omega^{+}\right),
$$

it is easy seen that

$$
\begin{aligned}
& M|\omega|\left(1-\mu^{2}\right) \int_{\Omega^{+}} \partial_{x_{2}}^{2} u \partial_{x_{2}}^{2} \varphi d x=|\omega| \int_{\Omega^{+}} f \varphi d x+ \\
& +\int_{0}^{c}\left(\int_{-1}^{0} g\left(x_{1}, x_{2}\right) d x_{2}\right) \varphi\left(x_{1}, 0\right) d x_{1} \quad \forall \varphi \in C^{\infty}\left(\overline{\Omega^{+}}\right): \varphi=0, D \varphi=0 \text { on } \Gamma,
\end{aligned}
$$

which, by density arguments, provides that $u \in W^{2}\left(\Omega^{+}\right)$is the unique solution of (4.3).

The following proposition is devoted to identify the limit problem in $\Omega^{-}$. 
Proposition 4.2. Let $u_{\varepsilon}$ be the solution of Problem (1.5). Assume (1.9) with $\left.l \in\right] 0,+\infty[$, and (1.6). Let $u_{0} \in L^{2}(] 0, c\left[, H_{\text {per }}^{2}(] 0,1[)\right)$ be satisfying Proposition 3.1. Then,

$$
\begin{aligned}
& M \frac{1-\mu^{2}}{l} \int_{] 0, c[\times] 0,1[} \partial_{y_{1}}^{2} u_{0}\left(x_{1}, y_{1}\right) \partial_{y_{1}}^{2} \varphi\left(x_{1}, y_{1}\right) d x_{1} d y_{1}= \\
& =\int_{] 0, c[\times] 0,1[}\left(\int_{-1}^{0} g\left(x_{1}, x_{2}\right) d x_{2}\right) \varphi\left(x_{1}, y_{1}\right) d x_{1} d y_{1}, \\
& \left.\forall \varphi \in L^{2}(] 0, c\left[, H_{p e r}^{2}(] 0,1[)\right): \varphi\left(x_{1}, y_{1}\right)=0 \text { in }\right] 0, c[\times \omega,
\end{aligned}
$$

where $\mu \in] 0, \frac{1}{2}[$ is the Poisson ratio, $M>0$ represents the flexural rigidity modulus of the plate (see Problem (1.5)), and $g \in L^{2}\left(\Omega^{-}\right)$is given by (1.6).

Proof. In the sequel, $\varepsilon$ takes values in a subsequence satisfying Proposition 3.1.

The proof of (4.9) will be performed in two steps.

At first, it will be proved that

$$
\left.\int_{-1}^{0} \int_{0}^{1} \xi\left(\left(x_{1}, x_{2}\right),\left(y_{1}, y_{2}\right)\right) d x_{2} d y_{2}=-\mu l^{-\frac{1}{2}} \partial_{y_{1}}^{2} u_{0}\left(x_{1}, y_{1}\right) \text { a.e. in }\right] 0, c[\times(] 0,1[),
$$

where $\xi \in L^{2}\left(\Omega^{-} \times\right] 0,1\left[^{2}\right)$ satisfies Proposition 3.1.

To this aim, choose

$$
v= \begin{cases}0 & \text { in } \Omega_{\varepsilon}^{+}, \\ h_{\varepsilon}^{\frac{3}{2}} x_{2}^{2} \varphi\left(x_{1}, \frac{x_{1}}{\varepsilon}\right) & \text { in } \Omega^{-}\end{cases}
$$

as test function in (1.5), where $\varphi\left(=\varphi\left(x_{1}, y_{1}\right)\right) \in C_{0}^{\infty}(] 0, c\left[\times(] 0,1[)\right.$ (point out that $\varphi\left(x_{1}, \cdot\right)$ 
admits an intrinsic 1 -periodic extension on $\mathbb{R})$. Then, it results that

$$
\begin{aligned}
& M h_{\varepsilon} \int_{\Omega^{-}} \partial_{x_{1}}^{2} u_{\varepsilon} \partial_{x_{1}}^{2}\left(h_{\varepsilon}^{\frac{3}{2}} x_{2}^{2} \varphi\left(x_{1}, \frac{x_{1}}{\varepsilon}\right)\right) d x+ \\
& +M h_{\varepsilon} \int_{\Omega^{-}} \partial_{x_{1}}^{2} u_{\varepsilon} \frac{1}{h_{\varepsilon}^{2}} \partial_{x_{2}}^{2}\left(h_{\varepsilon}^{\frac{3}{2}} x_{2}^{2} \varphi\left(x_{1}, \frac{x_{1}}{\varepsilon}\right)\right) d x+ \\
& +M h_{\varepsilon} \int_{\Omega^{-}} \frac{1}{h_{\varepsilon}^{2}} \partial_{x_{2}}^{2} u_{\varepsilon} \partial_{x_{1}}^{2}\left(h_{\varepsilon}^{\frac{3}{2}} x_{2}^{2} \varphi\left(x_{1}, \frac{x_{1}}{\varepsilon}\right)\right) d x+ \\
& +M h_{\varepsilon} \int_{\Omega^{-}} \frac{1}{h_{\varepsilon}^{2}} \partial_{x_{2}}^{2} u_{\varepsilon} \frac{1}{h_{\varepsilon}^{2}} \partial_{x_{2}}^{2}\left(h_{\varepsilon}^{\frac{3}{2}} x_{2}^{2} \varphi\left(x_{1}, \frac{x_{1}}{\varepsilon}\right)\right) d x+ \\
& +M(1-\mu) h_{\varepsilon} \int_{\Omega^{-}} 2 \frac{1}{h_{\varepsilon}} \partial_{x_{1} x_{2}}^{2} u_{\varepsilon} \frac{1}{h_{\varepsilon}} \partial_{x_{1} x_{2}}^{2}\left(h_{\varepsilon}^{\frac{3}{2}} x_{2}^{2} \varphi\left(x_{1}, \frac{x_{1}}{\varepsilon}\right)\right)+ \\
& -M(1-\mu) h_{\varepsilon} \int_{\Omega^{-}} \partial_{x_{1}}^{2} u_{\varepsilon} \frac{1}{h_{\varepsilon}^{2}} \partial_{x_{2}}^{2}\left(h_{\varepsilon}^{\frac{3}{2}} x_{2}^{2} \varphi\left(x_{1}, \frac{x_{1}}{\varepsilon}\right)\right)+ \\
& -M(1-\mu) h_{\varepsilon} \int_{\Omega^{-}} \frac{1}{h_{\varepsilon}^{2}} \partial_{x_{2}}^{2} u_{\varepsilon} \partial_{x_{1}}^{2}\left(h_{\varepsilon}^{\frac{3}{2}} x_{2}^{2} \varphi\left(x_{1}, \frac{x_{1}}{\varepsilon}\right)\right) d x= \\
& =h_{\varepsilon} \int_{\Omega^{-}} f_{\varepsilon} h_{\varepsilon}^{\frac{3}{2}} x_{2}^{2} \varphi\left(x_{1}, \frac{x_{1}}{\varepsilon}\right) d x
\end{aligned}
$$

for every $\varepsilon$.

Now, pass to the limit, as $\varepsilon \rightarrow 0$, in each term of (4.11).

From (1.9) with $l \in] 0,+\infty[$ and (2.2) it follows that

$$
\begin{aligned}
& \lim _{\varepsilon \rightarrow 0}\left(h_{\varepsilon} \int_{\Omega^{-}} \partial_{x_{1}}^{2} u_{\varepsilon} \partial_{x_{1}}^{2}\left(h_{\varepsilon}^{\frac{3}{2}} x_{2}^{2} \varphi\left(x_{1}, \frac{x_{1}}{\varepsilon}\right)\right) d x\right)= \\
& =\lim _{\varepsilon \rightarrow 0}\left(h_{\varepsilon} \int_{\Omega^{-}} h_{\varepsilon}^{\frac{1}{2}} \partial_{x_{1}}^{2} u_{\varepsilon} x_{2}^{2}\left(h_{\varepsilon} \partial_{x_{1}}^{2} \varphi+2 \frac{h_{\varepsilon}}{\varepsilon} \partial_{x_{1} y_{1}}^{2} \varphi+\frac{h_{\varepsilon}}{\varepsilon^{2}} \partial_{y_{1}}^{2} \varphi\right)\left(x_{1}, \frac{x_{1}}{\varepsilon}\right) d x\right)=0 .
\end{aligned}
$$

From (1.9) with $l \in] 0,+\infty[$ and (3.8) it follows that

$$
\begin{aligned}
& \lim _{\varepsilon \rightarrow 0} \int_{\Omega^{-}} h_{\varepsilon} \partial_{x_{1}}^{2} u_{\varepsilon} \frac{1}{h_{\varepsilon}^{2}} \partial_{x_{2}}^{2}\left(h_{\varepsilon}^{\frac{3}{2}} x_{2}^{2} \varphi\left(x_{1}, \frac{x_{1}}{\varepsilon}\right)\right) d x=\lim _{\varepsilon \rightarrow 0} \int_{\Omega^{-}} h_{\varepsilon}^{\frac{1}{2}} \partial_{x_{1}}^{2} u_{\varepsilon} 2 \varphi\left(x_{1}, \frac{x_{1}}{\varepsilon}\right) d x= \\
& =2 l^{-\frac{1}{2}} \int_{[0, c[\times] 0,1[} \partial_{y_{1}}^{2} u_{0}\left(x_{1}, y_{1}\right) \varphi\left(x_{1}, y_{1}\right) d x_{1} d y_{1} .
\end{aligned}
$$


From (1.9) with $l \in] 0,+\infty[$ and (3.2) it follows that

$$
\begin{aligned}
& \lim _{\varepsilon \rightarrow 0} \int_{\Omega^{-}} h_{\varepsilon} \frac{1}{h_{\varepsilon}^{2}} \partial_{x_{2}}^{2} u_{\varepsilon} \partial_{x_{1}}^{2}\left(h_{\varepsilon}^{\frac{3}{2}} x_{2}^{2} \varphi\left(x_{1}, \frac{x_{1}}{\varepsilon}\right)\right) d x= \\
& =\lim _{\varepsilon \rightarrow 0} \int_{\Omega^{-}} \partial_{x_{2}}^{2} u_{\varepsilon} x_{2}^{2}\left(h_{\varepsilon}^{\frac{1}{2}} \partial_{x_{1}}^{2} \varphi+2 \frac{h_{\varepsilon}^{\frac{1}{2}}}{\varepsilon} \partial_{x_{1} y_{1}}^{2} \varphi+\frac{h_{\varepsilon}^{\frac{1}{2}}}{\varepsilon^{2}} \partial_{y_{1}}^{2} \varphi\right)\left(x_{1}, \frac{x_{1}}{\varepsilon}\right) d x=0 .
\end{aligned}
$$

From (3.9) it follows that

$$
\begin{aligned}
& \lim _{\varepsilon \rightarrow 0} \int_{\Omega^{-}} h_{\varepsilon} \frac{1}{h_{\varepsilon}^{2}} \partial_{x_{2}}^{2} u_{\varepsilon} \frac{1}{h_{\varepsilon}^{2}} \partial_{x_{2}}^{2}\left(h_{\varepsilon}^{\frac{3}{2}} x_{2}^{2} \varphi\left(x_{1}, \frac{x_{1}}{\varepsilon}\right)\right) d x=\lim _{\varepsilon \rightarrow 0} \int_{\Omega^{-}} \frac{1}{h_{\varepsilon}^{\frac{3}{2}}} \partial_{x_{2}}^{2} u_{\varepsilon} 2 \varphi\left(x_{1}, \frac{x_{1}}{\varepsilon}\right) d x= \\
& =2 \int_{\left.\Omega^{-} \times\right] 0,1\left[^{2}\right.} \xi\left(\left(x_{1}, x_{2}\right),\left(y_{1}, y_{2}\right)\right) \varphi\left(x_{1}, y_{1}\right) d\left(x_{1}, x_{2}\right) d\left(y_{1}, y_{2}\right) .
\end{aligned}
$$

From (1.9) with $l \in] 0,+\infty[$ and (3.2) it follows that

$$
\begin{aligned}
& \lim _{\varepsilon \rightarrow 0} \int_{\Omega^{-}} h_{\varepsilon} 2 \frac{1}{h_{\varepsilon}} \partial_{x_{1} x_{2}}^{2} u_{\varepsilon} \frac{1}{h_{\varepsilon}} \partial_{x_{1} x_{2}}^{2}\left(h_{\varepsilon}^{\frac{3}{2}} x_{2}^{2} \varphi\left(x_{1}, \frac{x_{1}}{\varepsilon}\right)\right) d x= \\
& \lim _{\varepsilon \rightarrow 0} \int_{\Omega^{-}} 4 \partial_{x_{1} x_{2}}^{2} u_{\varepsilon} x_{2}\left(h_{\varepsilon}^{\frac{1}{2}} \partial_{x_{1}} \varphi+\frac{h_{\varepsilon}^{\frac{1}{2}}}{\varepsilon} \partial_{y_{1}} \varphi\right)\left(x_{1}, \frac{x_{1}}{\varepsilon}\right) d x=0 .
\end{aligned}
$$

From (1.6) it follows that

$$
\lim _{\varepsilon \rightarrow 0} \int_{\Omega^{-}} h_{\varepsilon} f_{\varepsilon} h_{\varepsilon}^{\frac{3}{2}} x_{2}^{2} \varphi\left(x_{1}, \frac{x_{1}}{\varepsilon}\right) d x=0 .
$$

Then, by passing to the limit, as $\varepsilon \rightarrow 0$, in (4.11) and by making use of $(4.12) \div(4.17)$, one obtains that

$$
\begin{aligned}
& 2 l^{-\frac{1}{2}} \int_{] 0, c[\times] 0,1[} \partial_{y_{1}}^{2} u_{0}\left(x_{1}, y_{1}\right) \varphi\left(x_{1}, y_{1}\right) d x_{1} d y_{1}+ \\
& +2 \int_{\left.\Omega^{-} \times\right] 0,1\left[^{2}\right.} \xi\left(\left(x_{1}, x_{2}\right),\left(y_{1}, y_{2}\right)\right) \varphi\left(x_{1}, y_{1}\right) d\left(x_{1}, x_{2}\right) d\left(y_{1}, y_{2}\right)+ \\
& -(1-\mu) 2 l^{-\frac{1}{2}} \int_{] 0, c[\times] 0,1[} \partial_{y_{1}}^{2} u_{0}\left(x_{1}, y_{1}\right) \varphi\left(x_{1}, y_{1}\right) d x_{1} d y_{1}=0, \quad \forall \varphi \in C_{0}^{\infty}(] 0, c[\times(] 0,1[)),
\end{aligned}
$$

that is (4.10).

Now, to prove (4.9), choose $v=\varphi\left(x_{1}, \frac{x_{1}}{\varepsilon}\right)$, as test function in $(1.5)$, where $\varphi\left(=\varphi\left(x_{1}, y_{1}\right)\right)$ $\in C^{\infty}\left([0, c], C_{\text {per }}^{\infty}([0,1])\right)$ such that $\varphi\left(x_{1}, y_{1}\right)=0$ in $[0, c] \times \bar{\omega}$. Then, it results that

$$
\begin{aligned}
& M h_{\varepsilon} \int_{\Omega^{-}} \partial_{x_{1}}^{2} u_{\varepsilon} \partial_{x_{1}}^{2}\left(\varphi\left(x_{1}, \frac{x_{1}}{\varepsilon}\right)\right) d x+M h_{\varepsilon} \int_{\Omega^{-}} \frac{1}{h_{\varepsilon}^{2}} \partial_{x_{2}}^{2} u_{\varepsilon} \partial_{x_{1}}^{2}\left(\varphi\left(x_{1}, \frac{x_{1}}{\varepsilon}\right)\right) d x+ \\
& -M(1-\mu) h_{\varepsilon} \int_{\Omega^{-}} \frac{1}{h_{\varepsilon}^{2}} \partial_{x_{2}}^{2} u_{\varepsilon} \partial_{x_{1}}^{2}\left(\varphi\left(x_{1}, \frac{x_{1}}{\varepsilon}\right)\right) d x=h_{\varepsilon} \int_{\Omega^{-}} f_{\varepsilon} \varphi\left(x_{1}, \frac{x_{1}}{\varepsilon}\right) d x,
\end{aligned}
$$


for every $\varepsilon$.

Pass to the limit, as $\varepsilon \rightarrow 0$, in each term of (4.18).

From (1.9) with $l \in] 0,+\infty[$ and (3.8) it follows that

$$
\begin{aligned}
& \lim _{\varepsilon \rightarrow 0} \int_{\Omega^{-}} h_{\varepsilon} \partial_{x_{1}}^{2} u_{\varepsilon} \partial_{x_{1}}^{2}\left(\varphi\left(x_{1}, \frac{x_{1}}{\varepsilon}\right)\right) d x= \\
& =\lim _{\varepsilon \rightarrow 0} \int_{\Omega^{-}} \frac{h_{\varepsilon}^{\frac{1}{2}}}{\varepsilon^{2}} \varepsilon^{2} \partial_{x_{1}}^{2} u_{\varepsilon}\left(h_{\varepsilon}^{\frac{1}{2}} \partial_{x_{1}}^{2} \varphi+2 \frac{h_{\varepsilon}^{\frac{1}{2}}}{\varepsilon} \partial_{x_{1} y_{1}}^{2} \varphi+\frac{h_{\varepsilon}^{\frac{1}{2}}}{\varepsilon^{2}} \partial_{y_{1}}^{2} \varphi\right)\left(x_{1}, \frac{x_{1}}{\varepsilon}\right) d x= \\
& =\frac{1}{l} \int_{[0, c[\times] 0,1[} \partial_{y_{1}}^{2} u_{0}\left(x_{1}, y_{1}\right) \partial_{y_{1}}^{2} \varphi\left(x_{1}, y_{1}\right) d x_{1} d y_{1} .
\end{aligned}
$$

From (1.9) with $l \in] 0,+\infty[,(3.9)$ and (4.10) it follows that

$$
\begin{aligned}
& \lim _{\varepsilon \rightarrow 0} \int_{\Omega^{-}} h_{\varepsilon} \frac{1}{h_{\varepsilon}^{2}} \partial_{x_{2}}^{2} u_{\varepsilon} \partial_{x_{1}}^{2}\left(\varphi\left(x_{1}, \frac{x_{1}}{\varepsilon}\right)\right) d x= \\
& =\lim _{\varepsilon \rightarrow 0} \int_{\Omega^{-}} \frac{1}{h_{\varepsilon}^{\frac{3}{2}}} \partial_{x_{2}}^{2} u_{\varepsilon}\left(h_{\varepsilon}^{\frac{1}{2}} \partial_{x_{1}}^{2} \varphi+2 \frac{h_{\varepsilon}^{\frac{1}{2}}}{\varepsilon} \partial_{x_{1} y_{1}}^{2} \varphi+\frac{h_{\varepsilon}^{\frac{1}{2}}}{\varepsilon^{2}} \partial_{y_{1}}^{2} \varphi\right)\left(x_{1}, \frac{x_{1}}{\varepsilon}\right) d x= \\
& =\int_{\left.\Omega^{-} \times\right] 0,1\left[^{2}\right.} \xi\left(\left(x_{1}, x_{2}\right),\left(y_{1}, y_{2}\right)\right) \frac{1}{l^{\frac{1}{2}}} \partial_{y_{1}}^{2} \varphi\left(x_{1}, y_{1}\right) d\left(x_{1}, x_{2}\right) d\left(y_{1}, y_{2}\right)= \\
& =-\frac{\mu}{l} \int_{[0, c[\times] 0,1[} \partial_{y_{1}}^{2} u_{0}\left(x_{1}, y_{1}\right) \partial_{y_{1}}^{2} \varphi\left(x_{1}, y_{1}\right) d x_{1} d y_{1} .
\end{aligned}
$$

From (1.6) it follows that

$$
\lim _{\varepsilon \rightarrow 0} \int_{\Omega^{-}} h_{\varepsilon} f_{\varepsilon} \varphi\left(x_{1}, \frac{x_{1}}{\varepsilon}\right) d x=\int_{\left.\Omega^{-} \times\right] 0,1[} g\left(x_{1}, x_{2}\right) \varphi\left(x_{1}, y_{1}\right) d\left(x_{1}, x_{2}\right) d y_{1} .
$$

Then, by passing to the limit, as $\varepsilon \rightarrow 0$, in (4.18) and by making use of $(4.19) \div(4.21)$, one obtains that

$$
\begin{aligned}
& M \frac{1-\mu^{2}}{l} \int_{] 0, c[\times] 0,1[} \partial_{y_{1}}^{2} u_{0}\left(x_{1}, y_{1}\right) \partial_{y_{1}}^{2} \varphi\left(x_{1}, y_{1}\right) d x_{1} d y_{1}= \\
& =\int_{] 0, c[\times] 0,1[}\left(\int_{-1}^{0} g\left(x_{1}, x_{2}\right) d x_{2}\right) \varphi\left(x_{1}, y_{1}\right) d x_{1} d y_{1} \\
& \forall \varphi \in C^{\infty}\left([0, c], C_{p e r}^{\infty}([0,1])\right) \text { such that } \varphi\left(x_{1}, y_{1}\right)=0 \text { in }[0, c] \times \bar{\omega}
\end{aligned}
$$

which provides (4.9), by density arguments. 


\section{References}

[1] G. Allaire, Homogenization and Two-Scale Convergence. SIAM J. Math Anal. 23 (1992), 6, 1482-1518.

[2] Y. Amirat, O. Bodart, U. De Maio, A. Gaudiello, Asymptotic Approximation of the Solution of the Laplace Equation in a Domain with Highly Oscillating Boundary. SIAM J. Math Anal. 35 (2004), 6, 1598-1616.

[3] L. BAffico, C. ConcA, Homogenization of a Transmission Problem in Solid Mechanics. J. Math. Anal. Appl. 233 (1999), 2, 659-680.

[4] D. Blanchard, L. Carbone, A. Gaudiello, Homogenization of a Monotone Problem in a Domain with Oscillating Boundary. M2AN Math. Model. Numer. Anal. 33 (1999), 5, 1057-1070.

[5] D. Blanchard, A. Gaudiello, Homogenization of Highly Oscillating Boundaries and Reduction of Dimension for a Monotone Problem. ESAIM Control Optim. Calc. Var. 9 (2003), 449-460.

[6] D. Blanchard, A. Gaudiello, J. Mossino, Highly Oscillating Boundaries and Reduction of Dimension: the Critical Case. Preprint n. R04026, Laboratoire J.L. Lions, Université P. et M. Curie, (2004), Anal. Appl. (Singap.), 5 (2007), 2, 1-27, to appear.

[7] R. Brizzi, J. P. Chalot, Boundary Homogenization and Neumann Boundary Value Problem. Ricerche Mat. 46 (1997), 2, 341-387.

[8] P.G. Ciarlet, Plates and Junctions in Elastic Multistructures: An Asymptotic Analysis. Research in Applied Mathematics, 14. Masson, Paris; Springer-Verlag, Berlin, (1990).

[9] P.G. Ciarlet, P. Destuynder, A Justification of the Two-Dimensional Linear Plate Model. J. Mécanique 18 (1979), 2, 315-344.

[10] D. Cioranescu, J. Saint Jean Paulin, Homogenization of Reticulated Structures. Applied Mathematical Sciences, 139, Springer-Verlag, New York., (1999).

[11] A. Corbo Esposito, P. Donato, A. Gaudiello, C. Picard, Homogenization of the $p$-Laplacian in a Domain with Oscillating Boundary. Comm. Appl. Nonlinear Anal. 4 (1997), 4, 1-23.

[12] U. De Maio, A. Gaudiello, C. Lefter, Optimal Control for a Parabolic Problem in a Domain with Highly Oscillating Boundary. Applicable Analysis, 83 (2004), 12, 12451264.

[13] D. Duvaut, J. L. Lions, Les inéquations en mécanique et en physique. Dunod, Paris (1972). 
[14] A. Gaudiello, Homogenization of an Elliptic Transmission Problem. Adv. Math. Sci. Appl. 5 (1995), 2, 639-657.

[15] A. Gaudiello, R. Hadisi, C. Picard, Homogenization of the Ginzburg-Landau Equation in a Domain with Oscillating Boundary. Commun. Appl. Anal. 7 (2003), 2-3, 209-223.

[16] A. Gaudiello, E. Zappale, Junction in a Thin Multidomain for a Fourth Order Problem. MA AS: Math. Models Methods Appl. Sci., 16 (2006), 12, 1887-1918.

[17] J.B. Keller, J. Nevard, Homogenization of Rough Boundary and Interfaces. SIAM J. Appl. Math. 57 (1997), 6, 1660-1686.

[18] V.A. Kozlov, V.G. MA'zya, A.B. Movchan, Asymptotic Analysis of Fields in a Multi-Structure, Oxford Mathematical Monographs. Oxford Science Publications. The Clarendon Press, Oxford University Press, New York (1999).

[19] H. Le Dret, Problèmes variationnels dans les multi-domaines: modélisation des jonctions et applications. Research in Applied Mathematics, 19. Masson, Paris, (1991).

[20] T.A. MeL'NyK, Homogenization of the Poisson Equations in a Thick Periodic Junction. Z. Anal. Anwendungen 18 (1999), 4, 953-975.

[21] T.A. Mel'nyk, S.A. Nazarov, Asymptotic Structure of the Spectrum of the Neumann Problem in a Thin Comb-Like Domain. C. R. Acad. Sci. Paris Sér. I Math. 319 (1994), 1343-1348.

[22] T.A. Mel'Nyk, S.A. Nazarov, Asymptotics of the Neumann Spectral Problem Solution in a Domain of "Thick Comb" Type. J. Math. Sci. 85 (1997), 6, 2326-2346.

[23] G. Nguetseng, A General Convergence Result for a Functional Related to the Theory of Homogenization. SIAM J. Math Anal. 20 (1989), 3, 608-623.

[24] G. Panasenko, Asymptotic Analysis of Rod Structures. Kluwer Academic Publishers, (2003).

[25] O. Pironneau, Optimal Shape Design for Elliptic Systems, Lecture Notes in Computational Physics, Springer, New-York, (1984).

[26] L. Tartar, Cours Peccot, Collège de France (March 1977). Partially written in F. Murat, H-Convergence, Séminaire d'analyse fonctionnelle et numérique de l'Université d'Alger (1977-78). English translation in Mathematical Modelling of Composite Materials, A. Cherkaev and R.V. Kohn ed., Progress in Nonlinear Differential Equations and their Applications, Birkhäuser - Verlag (1997), 21-44.

[27] L. Trabucho , J.M. Viano, Mathematical Modelling of Rods Hand-book of Numerical Analysis, vol. 4, North-Holland, Amsterdam, (1996). 


\section{Dominique Blanchard}

Université de Rouen, UMR 6085, F-76821 Mont Saint Aignan, Cédex

France;

and

Laboratoire d'Analyse Numérique,

Université P. et M. Curie,

Case Courrier 187,

75252 Paris Cédex 05,

France.

e-mail: blanchar@ann.jussieu.fr

\section{Antonio Gaudiello}

DAEIMI,

Università degli Studi di Cassino,

via G. Di Biasio 43,

03043 Cassino (FR),

Italia.

e-mail: gaudiell@unina.it

\section{Taras A. Mel'nyk}

Kyiv Nat. Taras Shevchenko Univ., Volodymyrs'ka Str. 64,

01033 Kyiv,

Ukraine.

e-mail: melnyk@imath.kiev.ua 